\title{
Associação entre alterações do estado nutricional, perda dentária, uso de prótese e autopercepção das condições bucais referidas por idosos no município de São Paulo: Estudo SABE (2000 e 2006)
}

Juliana Magalhães da Cunha Rêgo

Dissertação revisada e apresentada ao Programa de Pós-Graduação Nutrição em Saúde Pública da Faculdade de Saúde Pública da Universidade de São Paulo, para obtenção do título de Mestre em Ciências.

Área de Concentração: Nutrição em Saúde Pública

Orientadora: Prof ${ }^{a}$ Dra ${ }^{\mathrm{a}}$ Maria de Fátima Nunes Marucci

São Paulo 


\section{$54629 / 2013$}

É, expressamente, proibida a comercialização deste documento, tanto na sua forma impressa, como eletrônica. Sua reprodução total ou parcial é permitida, exclusivamente, para fins acadêmicos e científicos, desde que na reprodução figure a identificação do autor, título, instituição e ano da tese/dissertação. 


\section{DEDICATÓRIA}

Aos meus amados pais,

Luís Holanda e Ana Maria Rêgo,

grandes incentivadores e facilitadores desse sonho. 


\section{AGRADECIMENTOS}

A Deus e à Nossa Mãe, pelo amor maior que tens por mim, por toda a força e a determinação que me fizeram descobrir em mim mesma, a continuar nessa luta, chegar até aqui e ser uma pessoa melhor, não pelo título que irei conquistar, mas pelo muito que aprendi na minha vida pessoal, com essa oportunidade.

Aos meus pais, Luís Holanda do Rêgo e Ana Maria Magalhães da Cunha Rêgo, que não mediram forças para que fosse possível esse sonho, o apoio e o incentivo, principalmente nas quedas, o amor incondicional e a companhia sempre tão presente e, ao mesmo tempo, tão distante, mas nunca longe. Amo demais.

Ao Leonardo Mascarenhas, meu noivo, pelo companheirismo, carinho, paciência, incentivo e amor, que me dedicaste nesses anos distante fisicamente. Em breve, estaremos juntos para sempre. "Perto está quem mora dentro do coração"!

Aos professores da Faculdade de Saúde Pública, que tanto me ensinaram e me apoiaram, em especial, à minha orientadora, Maria de Fátima Nunes Marucci, pelos grandes ensinamentos, contribuições e oportunidade de fazer parte do seu grupo de estudos.

Aos meus colegas de orientação, principalmente à Daniele Lima de Alencar Castelo, me incentivando a me manter sempre focada nos meus sonhos profissionais e me mostrando que é possível conciliar com o lado pessoal.

Aos meus amigos cearenses, à minha TURMASSA, pois a amizade verdadeira é para sempre, na alegria e na tristeza, longe ou perto, em especial ao Antônio Augusto Ferreira Carioca, grande amigo, companheiro, vizinho de república e aprendiz de muita coisa em comum; e à minha amiga e companheira de república Joana Bisol Balardin, pelos exemplos, pelos ensinamentos e pela forma que me ensinou para viver longe de casa.

A Coordenação de Aperfeiçoamento de Pessoal de Nível Superior CAPES, pelo apoio financeiro da bolsa de estudos. 


\section{EPÍGRAFE}

"Quando Deus tira algo de você, ELe não o está punindo, mas apenas abrindo suas mãos para que rece6a algo muito melhor".

(Desconhecido)

"Não acrescente dias a sua vida, mas vida aos seus dias".

(Harry Benjamin) 
RÊGO JMC. Associação entre alterações do estado nutricional, perda dentária, uso de prótese e autopercepção das condições bucais de idosos no município de São Paulo: Estudo SABE (2000 e 2006). [Dissertação de mestrado]. São Paulo: Faculdade de Saúde Pública/Universidade de São Paulo; 2013.

\section{RESUMO}

Objetivo: Verificar a associação entre alterações do estado nutricional, perda dentária, uso de prótese e autopercepção das condições bucais em uma coorte de idosos, segundo sexo e idade. Métodos: Foram analisados 773 idosos ( $\geq 60$ anos), de ambos os sexos, do Estudo SABE: Saúde, Bem-estar e Envelhecimento, epidemiológico, de base domiciliar, realizado no município de São Paulo, em 2000 e 2006. As variáveis de estudo foram: alterações no estado nutricional - segundo Índice de Massa Corporal (IMC), considerando baixo peso $\left(\leq 23 \mathrm{~kg} / \mathrm{m}^{2}\right)$, peso adequado para estatura $\left(>23 \mathrm{e}<28 \mathrm{~kg} / \mathrm{m}^{2}\right)$ e excesso de peso $\left(\geq 28 \mathrm{~kg} / \mathrm{m}^{2}\right)$, em 2000 e 2006; perda dentária ( $<16$ ou $\geq 16$ dentes); uso de prótese dentária ( $\operatorname{sim} /$ não); autopercepção das condições bucais, segundo Geriatric Oral Health Assessment Index (GOHAI), considerando más condições bucais (GOHAI < 50 pontos), regulares (GOHAI de 51 a 56 pontos) e boas (GOHAI de 57 a 60 pontos), sexo e grupos etários (60-74 e $\geq 75$ anos), em 2000. Verificou-se a associação por meio do teste de Rao-Scott e da análise de regressão logística multinomial ( $\mathrm{p}<0,05$ e IC95\%), utilizando o programa estatístico STATA 10.1. Resultados: Dos idosos analisados, $59,94 \%$ eram mulheres e $80,55 \%$ do grupo 60 a 74 anos. Identificou-se diminuição da proporção de idosos com excesso de peso (37\% antes, $29 \%$ depois) e aumento daquela com baixo peso (16\% antes, $26 \%$ depois). Verificou-se menor risco para excesso de peso em 2006, aqueles que apresentaram peso adequado, em 2000 e referiram condições bucais regulares $[R R=0,31(0,14-0,69)]$, e maior risco para peso adequado em 2006, nos homens, que apresentaram excesso de peso em 2000 $[R R=2,23(1,09-4,55)]$. Conclusão: Constatou-se associação entre alterações do estado nutricional, condições bucais regulares, segundo a autopercepção, e sexo masculino, em 2000 e 2006.

Palavras-chave: idoso; estado nutricional; autopercepção; GOHAI; condições bucais. 
REGGO, J. M. C. Association between changes of nutritional status, tooth loss, use of dental prosthesis and self-perceived oral health among elderly people in São Paulo city - SABE Survey (2000 - 2006). [Dissertation] São Paulo: Faculdade de Saúde Pública/Universidade de São Paulo; 2013.

\begin{abstract}
Objective: To investigate the association between changes of nutritional status and tooth loss, use of dental prosthesis and self-perceived oral health among elderly people, by gender and age. Methods: The sample consisted of 773 elderly people $(\geq$ 60 years) community-dwelling, both genders, participants of Health, Wellbeing and Aging Cohort Study (SABE Survey), epidemiological, home-based, from the city of São Paulo, from 2000 to 2006 . The variables analyzed were: changes of nutritional status: by body mass index $\left(B M I-k g / \mathrm{m}^{2}\right)$, considering underweight $\left(\leq 23 \mathrm{~kg} / \mathrm{m}^{2}\right)$, appropriate weight for height $\left(>23\right.$ and $<28 \mathrm{~kg} / \mathrm{m}^{2}$ ) and overweight $\left(\geq 28 \mathrm{~kg} / \mathrm{m}^{2}\right.$ ), to 2000 from 2006; tooth loss (< or $\geq 16$ tooth); use of dental prosthesis (yes/no), selfperceived oral health, according to Geriatric Oral Health Assessment Index (GOHAI), considering worse oral conditions ( $<50$ points), regular (51-56 points) and good (57-60 points), gender and age groups (60-74 and $\geq 75$ ), in 2000 . The association was verified by test of Rao-Scott and multinomial logistic regression analysis ( $p<0.05$ and IC95\%) using software STATA 10.1. Results: Of elderly analyzed, $59.94 \%$ were women and $80.55 \%$ of the group 60 to 74 y. From 2000 to 2006 , it was observed a decrease in the proportion of overweight (37 to 29\%) and an increase of underweight (16 to 26\%) in the sample of older adults. Lower risk of overweight in 2006 were predicted by appropriate weight for height and regular oral conditions in 2000 [RR $=0.31(0.14-0.69)]$. Specifically, overweight elderly males in 2000 exhibited higher risk for appropriate weight for height in 2006 [RR $=2.23(1.09$ to 4.55)]. Conclusion: From 2000 to 2006, there were significant associations between nutritional status, regular oral conditions, self-perception and males.
\end{abstract}

Keywords: elderly people; status nutritional; self-perception; GOHAI (Geriatric Oral Health Assessment Index); oral health. 


\section{LISTA DE FIGURAS}

Figura 1 Percentual da população com 60 anos ou mais em 2006................. 15

Figura 2 Percentual da população com 60 anos ou mais em 2050................. 16

Figura 3 Distribuição da população mundial (\%) de 60 anos ou mais por

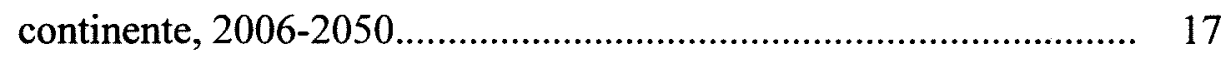

Figura 4 Composição absoluta da população, por sexo e idade. Brasil,

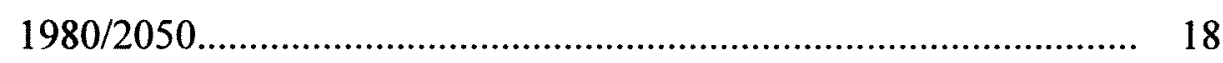

Figura 5 População de 80 anos ou mais, segundo sexo, em milhões, de 1980

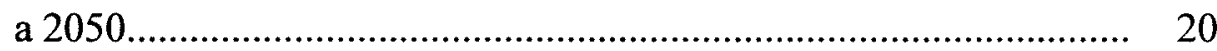

Figura 6 Evolução do índice de envelhecimento da população - Brasil, $1980 / 2050$

Figura 7 Média do CPO-D e respectivos componentes segundo grupo etário. Brasil, 2010................................................................... 27

Figura 8 Fluxograma de seleção da amostra deste estudo............................ 36

Figura 9 Algoritmo para o desenho deste estudo....................................... 38 


\section{LISTA DE QUADROS}

Quadro 1 Seções do questionário, utilizadas no Estudo SABE, em 2000.......... 34

Quadro 2 Classificação do estado nutricional dos idosos, segundo valores de IMC ................................................................................. 37

Quadro 3 Categorização da perda dentária........................................................ 38 


\section{LISTA DE TABELAS}

Tabela 1 Distribuição da proporção dos idosos das variáveis independentes, sexo e grupos etários. Estudo SABE, São Paulo/Brasil, 2000 .

Tabela 2 Associação do estado nutricional dos idosos em 2000 e 2006 e variáveis independentes. Estudo SABE, São Paulo/Brasil, 20002006

Tabela 3 Associação entre estado nutricional em 2006, e as variáveis independentes, segundo risco relativo, dos idosos com baixo peso em 2000. Estudo SABE, São Paulo/Brasil, 2000-2006

Tabela 4 Associação entre estado nutricional em 2006, e as variáveis sexo e grupos etários, segundo risco relativo, dos idosos com baixo peso em 2000. Estudo SABE, São Paulo/Brasil, 2000-2006........

Tabela 5 Associação entre estado nutricional em 2006, e as variáveis, segundo risco relativo, dos idosos com peso adequado em 2000. Estudo SABE, São Paulo/Brasil, 2000-2006.

Tabela 6 Associação entre estado nutricional, em 2006, e as variáveis sexo e grupos etários, segundo risco relativo, dos idosos com peso adequado, em 2000. Estudo SABE, São Paulo/Brasil, 20002006

Tabela 7 Associação entre estado nutricional, em 2006, e as variáveis independentes, segundo risco relativo, dos idosos com excesso de peso, em 2000. Estudo SABE, São Paulo/Brasil, 2000-2006...

Tabela 8 Associação entre estado nutricional, em 2006, e as variáveis sexo e grupos etários, segundo risco relativo, dos idosos com excesso de peso, em 2000. Estudo SABE, São Paulo/Brasil, 2000-2006... 


\section{LISTA DE SIGLAS E ABREVIATURAS}

\begin{tabular}{|c|c|}
\hline Abreviatura & Descrição \\
\hline BHAS - & Bambui Health and Aging Study \\
\hline COEP - & Comitê de Ética em Pesquisa \\
\hline CONEP - & Comissão Nacional de Ética em Pesquisa \\
\hline CPO-D - & Índice de dentes cariados, perdidos e obturados \\
\hline DP - & desvio-padrão \\
\hline FAPESP - & Fundação de Amparo à Pesquisa do Estado de São Paulo \\
\hline FSP - & Faculdade de Saúde Pública \\
\hline GOHAI - & Geriatric Oral Health Assessment Index \\
\hline IMC - & Índice de Massa Corporal \\
\hline ISA - Capital - & Inquérito de Saúde de Base Populacional \\
\hline kg & quilogramas \\
\hline $\mathbf{m}$ & metros \\
\hline MS - & Ministério da Saúde \\
\hline NDNS - & British National Diet and Nutrition Survey \\
\hline NR - & Não responderam \\
\hline NS - & Não sabem \\
\hline OMS - & Organização Mundial da Saúde \\
\hline OPAS - & Organização Pan-Americana de Saúde \\
\hline PNSN - & Pesquisa Nacional sobre Saúde e Nutrição \\
\hline RR - & Risco Relativo \\
\hline SABE - & Saúde, Bem-estar e Envelhecimento \\
\hline USP - & Universidade de São Paulo \\
\hline
\end{tabular}




\section{SUMÁRIO}

1 INTRODUÇÃO

$\begin{array}{ll}1.1 \text { ENVELHECIMENTO POPULACIONAL } & 15\end{array}$

1.2 ESTADO NUTRICIONAL DE IDOSOS 22

1.3 CONDIÇÕES BUCAIS 25

2 OBJETIVO 30

3 CASUÍSTICA E MÉTOdOS 32

3.1 DELINEAMENTO DO ESTUDO 33

3.2 POPULAÇÃO DE ESTUDO

3.3 VARIÁVEIS DE ESTUDO 36

3.3.1 Variável dependente 36

3.3.2 Variáveis independentes $\quad 38$

3.4 ANÁLISES ESTATÍSTICAS

3.5 ASPECTOS ÉTICOS 40

4 RESULTADOS 41

5 DISCUSSÃO

6 CONCLUSÃo

REFERÊNCIAS

ANEXOS

CURRÍCULO LATTES - ORIENTADORA

CURRÍCULO LATTES - ALUNA 
1. Introdução 


\section{INTRODUÇÃO}

\subsection{ENVELHECIMENTO POPULACIONAL}

O envelhecimento populacional é um fenômeno natural, irreversível e mundial, e acontece rapidamente: o número de pessoas com 60 anos ou mais dobrará, proporcionalmente, passando de $11 \%$ em 2006, para $22 \%$ em 2050, havendo países na América do Norte, Europa, Ásia e Oceania onde esse percentual pode superar $30 \%$ da população em 2050 (UNITED NATIONS, 2006) (Figuras 1 e 2).

Figura 1. Percentual da população com 60 anos ou mais em 2006.

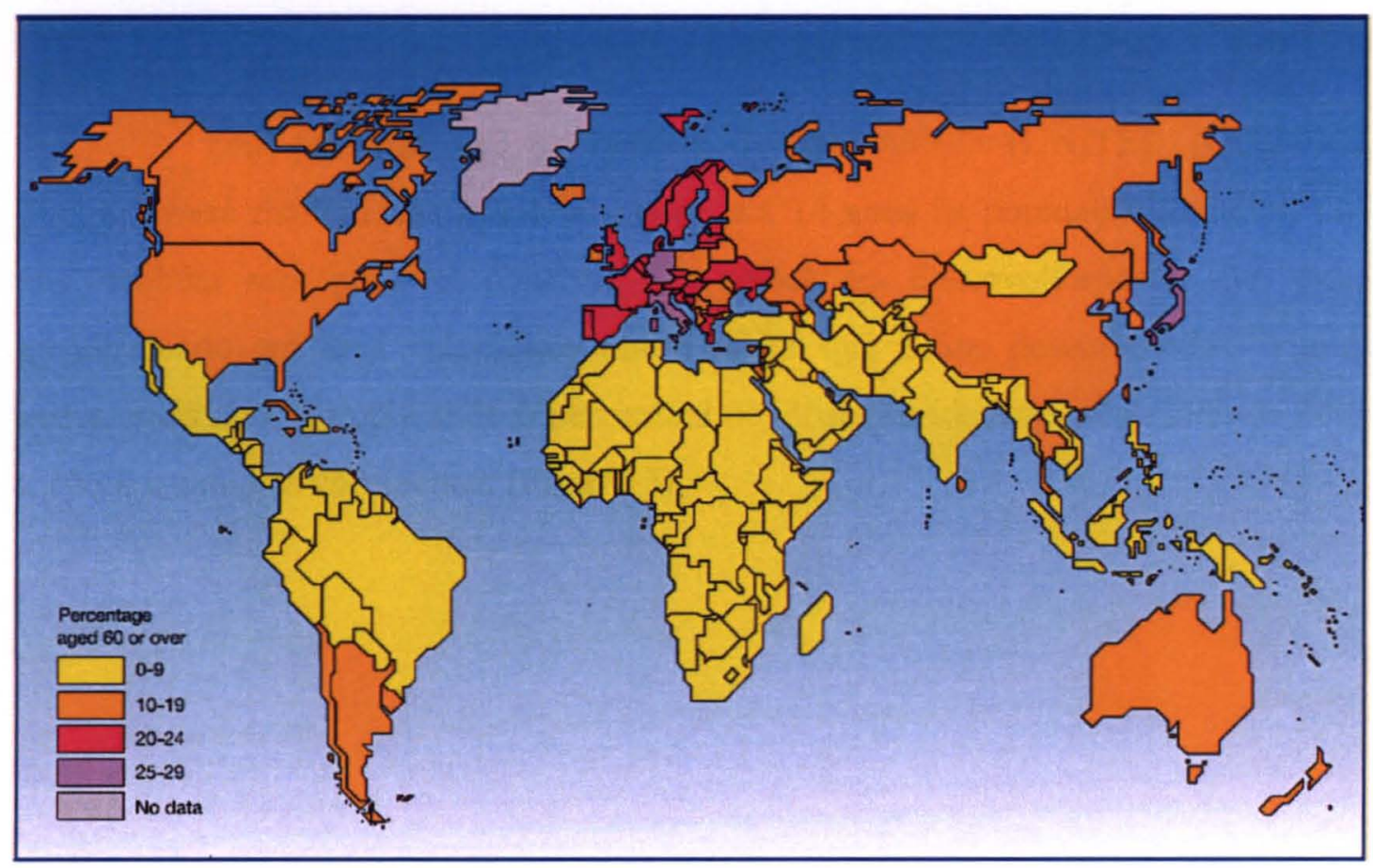

Fonte: UNITED NATIONS (2006). 
Figura 2. Percentual da população com 60 anos ou mais em 2050.

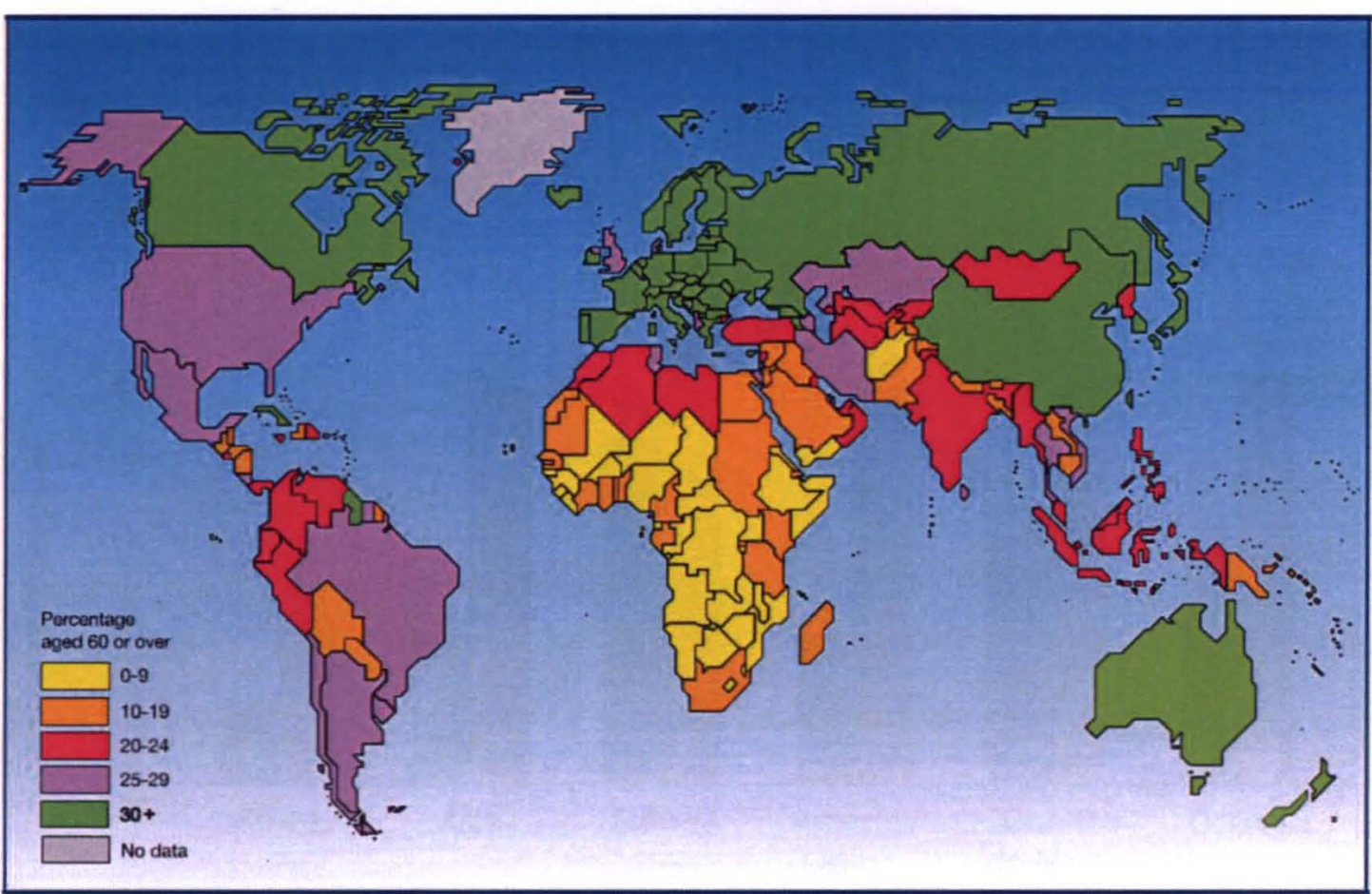

Fonte: UNITED NATIONS (2006).

Pela primeira vez na história da humanidade (UNITED NATIONS, 2006), haverá mais idosos que crianças de 0 a 14 anos na população mundial, fato que também será possível observar nos países em desenvolvimento, que estão envelhecendo em uma velocidade muito maior que a dos desenvolvidos. Muitas vezes, mais do que duplicando o percentual de idosos residentes, no período de 2006 a 2050, em alguns continentes (Figura 3). 
Figura 3. Distribuição da população mundial (\%) de 60 anos ou mais por continente, 2006-2050.

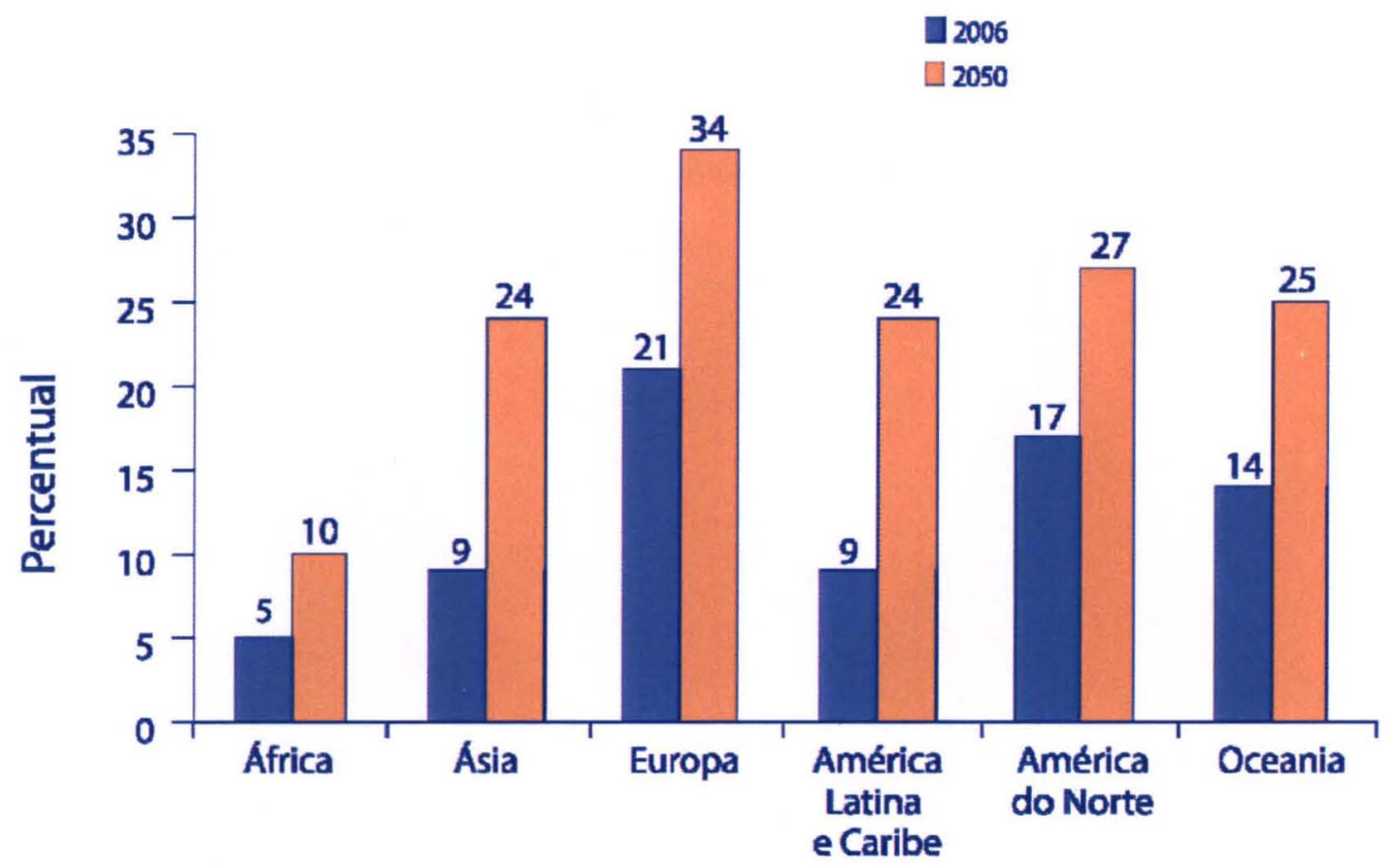

Fonte: UNITED NATIONS (2006).

O aumento da expectativa de vida média (de aproximadamente 73 anos que aumentou mais de 25 anos entre 1950 e 2010, nivelada com a de países mais desenvolvidos), juntamente com o efeito combinado da redução dos níveis da fecundidade e da mortalidade (RAMOS, 2012), são as causas das transformações no padrão etário da população brasileira (CAMARANO, 2002), sobretudo a partir de meados dos anos de 1980 (IBGE, 2008; BRASIL, 2010).

A pirâmide etária do Brasil foi completamente transformada nos últimos trinta anos, de 1980 a 2010 (RAMOS, 2012).

O formato tipicamente triangular da pirâmide populacional, com uma base alargada, está cedendo lugar a uma pirâmide populacional característica de uma sociedade em acelerado processo de envelhecimento, que se caracteriza pela redução da participação relativa de crianças e jovens, acompanhada do aumento do peso proporcional dos adultos e, particularmente, dos idosos, que atualmente é o grupo 
populacional que mais cresce (mais que dobrou de 1980 a 2000) (IBGE, 2008; BRASIL, 2010; RAMOS, 2012) (Figura 4).

Figura 4. Composição absoluta da população, por sexo e idade. Brasil - 1980/2050 (continua).

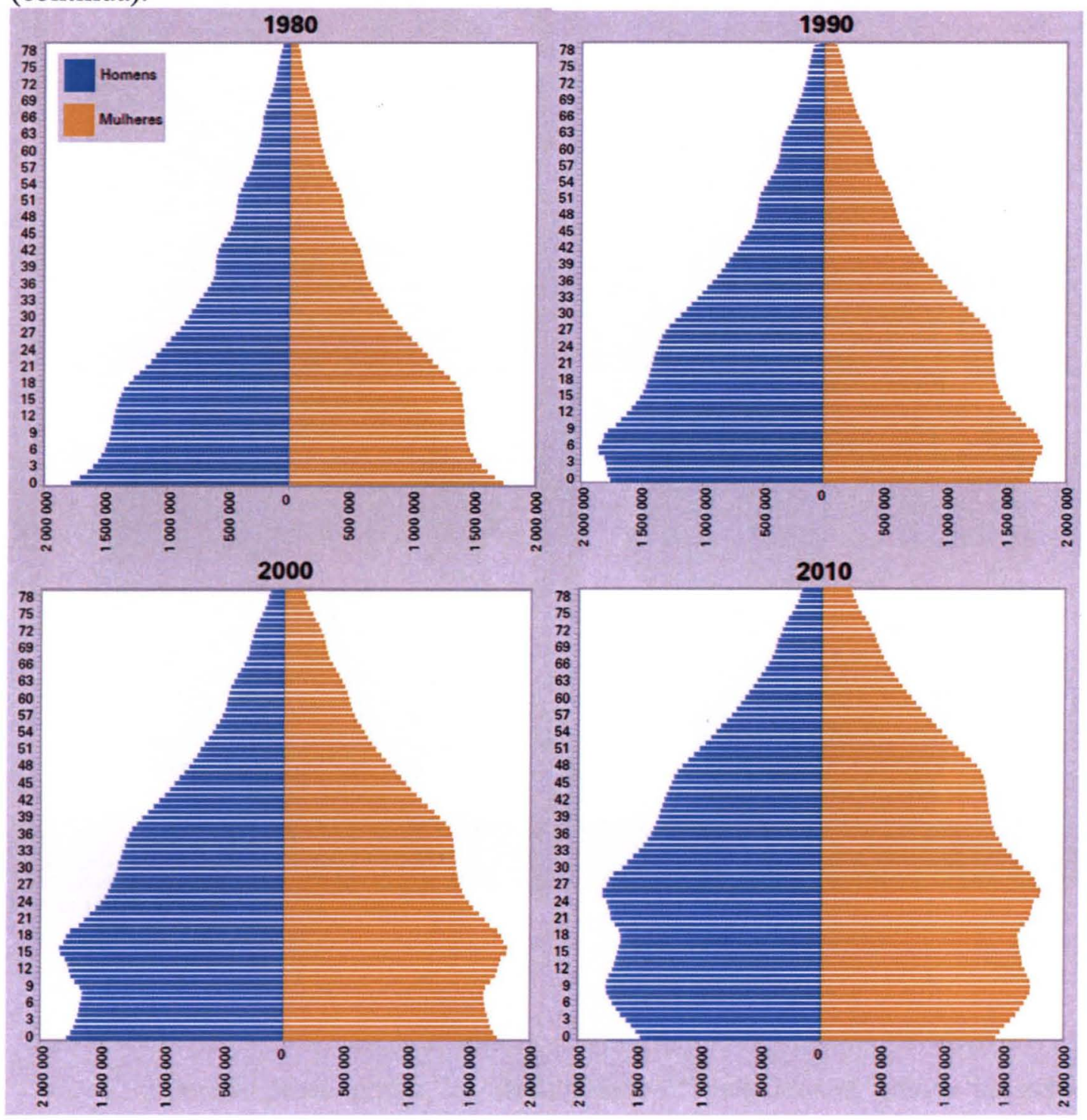


Figura 4. Composição absoluta da população, por sexo e idade. Brasil - 1980/2050 (conclusão).
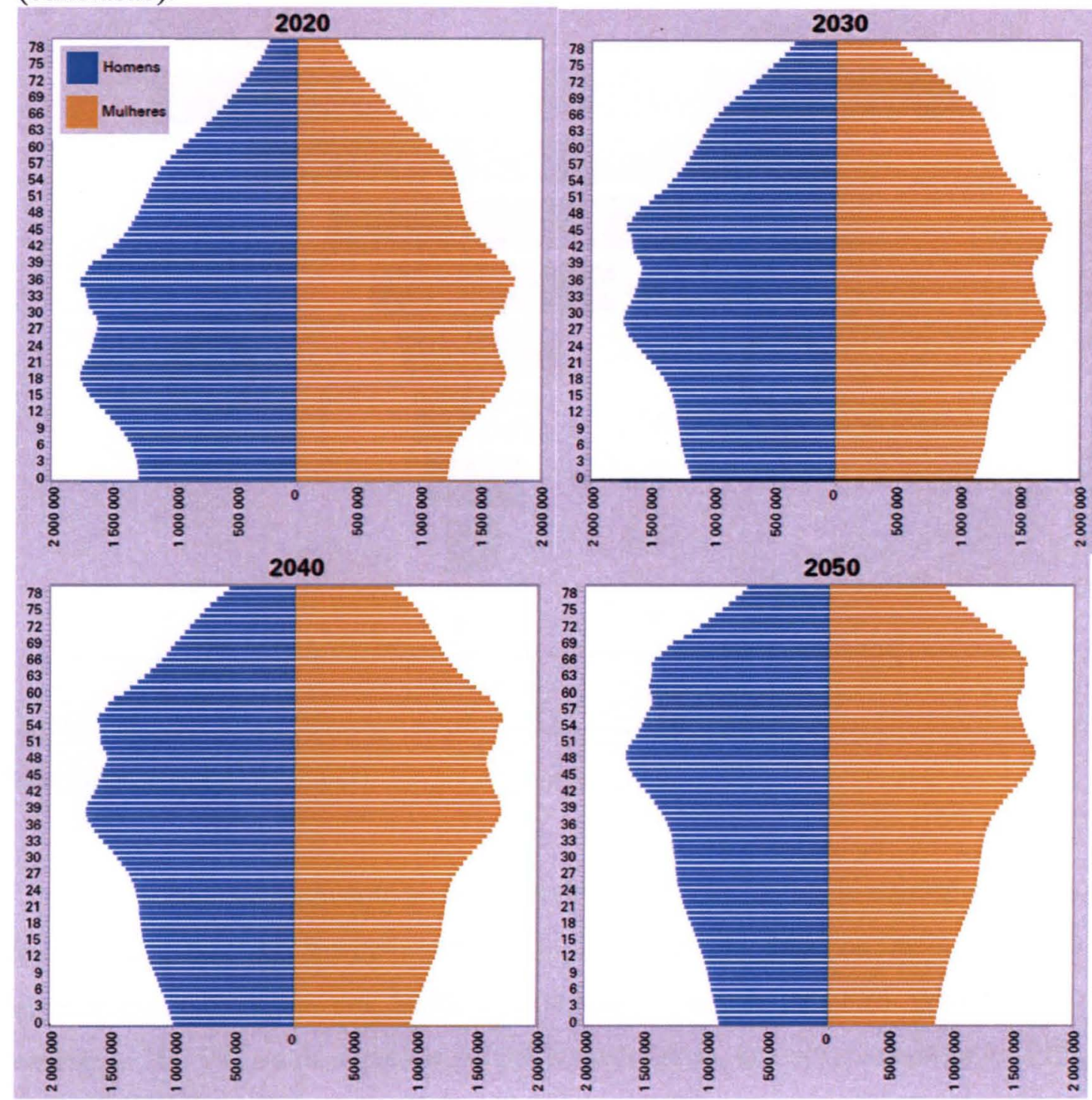

Fonte: IBGE (2008).

Dentro desse grupo, os denominados "mais idosos, muito idosos ou idosos em velhice avançada" (acima de 80 anos), também vêm aumentando proporcionalmente e de maneira mais acelerada, constituindo a parcela da população que mais cresce, sendo hoje mais de $12 \%$ da população idosa e a estimativa é que sejam 15 milhões de pessoas em 2050 (Figura 5) (IBGE, 2008; BRASIL, 2010; RAMOS, 2012). 
Figura 6. Evolução do índice de envelhecimento da população - Brasil - 1980/2050.

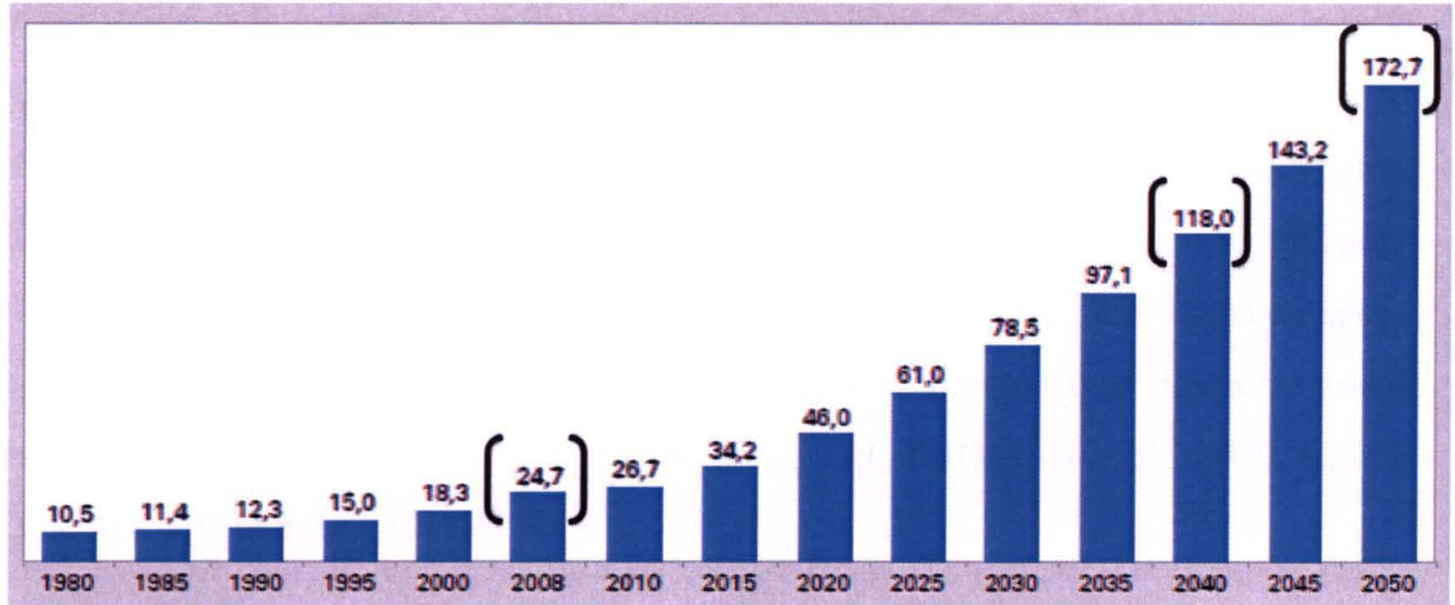

Fonte: IBGE (2008).

Nota: Índice de envelhecimento $=\{[$ Pop. $(65+) /$ Pop. $(0$ a 14) $] * 100\}: 1980 / 2050$.

O prolongamento da vida associado a melhores condições de saúde, em quase todo o mundo, tem levado a uma mudança de percepção do que vem a ser a última etapa da vida, que antes representava um processo de perdas, agora é considerado um momento propício para novas conquistas, possibilidades de aprendizagem e conhecimento (CAMARANO e PASINATO, 2004a), principalmente aliados a melhores condições de saúde, já que saúde para a população idosa não se restringe ao controle e à prevenção de agravos de doenças crônicas não transmissíveis, mas é a interação entre a saúde física, a saúde mental, a independência financeira, a capacidade funcional e o suporte social (RAMOS, 2002).

Existe uma heterogeneidade do grupo de idosos, devido às alterações e estilo de vida, que acarreta demandas diferenciadas (CAMARANO e PASINATO, 2004b), podendo estar relacionadas às mudanças no estado nutricional desta população.

Com o envelhecimento, ocorrem alterações morfológicas, bioquímicas, fisiológicas, comportamentais e psicossociais, que, apesar de serem consideradas comuns nesse processo, acarretam prejuízos significativos na forma de se alimentar, pois os indivíduos idosos têm risco aumentado para dieta inadequada (AHMED E HABOUBI, 2006), podendo influenciar no desenvolvimento de doenças associadas à 
má nutrição, desencadeando, por exemplo, doenças crônicas não transmissíveis, como obesidade, diabetes mellitus tipo 2, cardiopatias, dislipidemias e câncer, comprometendo direta ou indiretamente o estado nutricional dos idosos (PAPALÉO NETTO e BORGONOVI, 2002; FLORENTINO, 2002; WHO, 2003; COBAN, et al.; 2003; HOUSTON et al., 2009; LOEF e WALACH, 2012), que merece, portanto, atenção especial, pelas perdas de peso involuntárias, decorrente da redução de apetite (anorexia) e caquexia, muito comum no envelhecimento, que acarreta grande impacto no estado nutricional (ROUBENOFF, 1999; THOMAS et al., 2000; LEITECAVALCANTI et al., 2009).

\subsection{ESTADO NUTRICIONAL DE IDOSOS}

A avaliação do estado nutricional é de grande importância na identificação das alterações que acompanham o envelhecimento (BUENO et al., 2008). Para tanto, em revisão de Acuña e Cruz (2004), esta avaliação pode ser realizada por métodos convencionais e não convencionais, sendo os convencionais tradicionalmente utilizados em estudos epidemiológicos e na prática clínica. Os não convencionais apresentam limitações, como equipamentos de custo elevado e dificuldades na execução, no entanto, o melhor método depende dos objetivos da avaliação.

A antropometria, que faz parte dos convencionais, é um método muito utilizado em estudos epidemiológicos, sendo preconizada para estudos populacionais, pela Organização Mundial de Saúde (OMS) (ACUÑA e CRUZ, 2004) por não ser invasivo, ser de baixo custo operacional, seguro e ter valor preditivo acurado (LUKASKI, 1987).

O Índice de Massa Corporal (IMC) é o indicador antropométrico mais usado para avaliar o estado nutricional de idosos (CERVI et al., 2005), amplamente reconhecido por predizer risco para aumento da morbimortalidade (BUENO et al. 2008). 
O excesso de peso indica risco para doenças cardiovasculares, hipertensão arterial, doença isquêmica do coração, diabetes melito tipo 2, dislipidemias, câncer, apneia do sono e acidente vascular cerebral, colelitíase, osteoartrite (especialmente de joelhos), neoplasia maligna de mama pós-menopausa e de endométrio, esofagite de refluxo, hérnia de hiato e problemas psicológicos (WHO, 1995; WHO, 1998; MATSUDO, MATSUDO e BARROS NETO, 2000; OMERAN e MORLEY, 2000; CABRERA e JACOB FILHO, 2001).

O baixo peso, problema relevante em idosos por ser muito comum nessa fase (SILVA, RAUEN e MOREIRA, 2005), está associado ao declínio funcional, mostra riscos para doenças respiratórias e infecciosas, úlceras de pressão e deficiência de cicatrização de feridas, fraturas de quadril, além de prolongados períodos de recuperação e exacerbação de doenças, insuficiência cardíaca, diminuição da síntese de proteínas a nível hepático com produção de metabólitos anormais, diminuição da filtração glomerular e da produção de suco gástrico (McWHIRTER e PENNINGTON, 1994; WHO, 2000; MATSUDO, MATSUDO e BARROS NETO, 2000; OMERAN e MORLEY, 2000; CHAPMAN, 2006).

É possível encontrar diversos estudos utilizando o IMC para diagnóstico do estado nutricional. Inquéritos nacionais, como a Pesquisa Nacional sobre Saúde e Nutrição (PNSN) (TAVARES e ANJOS; 1999) e a Pesquisa de Orçamentos Familiares (POF) 2002/2003 (IBGE, 2004), utilizaram os valores propostos pela OMS (WHO, 1995; 1998).

Entretanto, não há um consenso sobre os valores adequados de IMC para se diagnosticar o estado nutricional da população idosa (SANTOS e SICHIERI, 2005), entretanto, há uma classificação, proposta pela Organização Pan-Americana de Saúde (OPAS), para valores a serem adotados para avaliar o estado nutricional de idosos em países da América Latina e Caribe (OPAS, 2001), onde o Brasil está inserido.

A idade tem um impacto importante na composição corporal (ELMADFA E MEYER, 2008), por isso que estudos como o de Sánchez-García et al. (2007) sugerem que a aplicação dos valores de IMC propostos pela WHO (1995; 
1998), que não são específicos para a população idosa, pode levar a uma superestimação do número de indivíduos com excesso de peso e uma subestimação de subnutrição.

Essa dificuldade de se padronizar valores de IMC é decorrente da mudança na composição corporal, com redução da massa magra e da massa gordurosa - de todos os compartimentos do corpo no envelhecimento (BURR e PHILLIPS, 1984), fato que conduz ao baixo peso/subnutrição, aumentando o risco para mortalidade, mas que não acontece da mesma forma e com a mesma intensidade em todos os idosos.

No Brasil, Tavares e Anjos (1999), com base nos dados da PNSN, realizada em 1989, em 363 municípios brasileiros, encontraram prevalências de baixo peso e excesso de peso, respectivamente, de 7,8\% e $30,4 \%$ em homens e de $8,4 \%$ e $50,2 \%$ em mulheres, sendo o excesso de peso mais prevalente em mulheres, em áreas urbanas das regiões Sul e Sudeste. Para a classificação do estado nutricional, os dados da PNSN foram analisando segundo os valores de referências propostos pela WHO (1995/1998), que, para baixo peso, o IMC $<18,5 \mathrm{~kg} / \mathrm{m}^{2}$, e para excesso de peso, IMC $\geq 25 \mathrm{~kg} / \mathrm{m}^{2}$.

Barreto, Passos e Lima-Costa (2003) constataram 12,8\% de idosos obesos (IMC $\geq 30 \mathrm{~kg} / \mathrm{m}^{2}$ ), e 14,4\%, com baixo peso (IMC $\leq 20 \mathrm{~kg} / \mathrm{m}^{2}$ ), em 1.443 idosos ( $\geq 60$ anos) do Projeto Bambuí: Estudo de Coorte de Base Populacional da Saúde dos Idosos, com residentes em Bambuí/MG, verificando que a obesidade era mais comum entre mulheres e que a prevalência decrescia com a idade, já que os participantes foram acompanhados anualmente desde 1997 (COSTA et al., 2002).

O Inquérito de Saúde de Base Populacional (ISA - Capital), realizado em 2008, na cidade de São Paulo/SP, identificou 44\% de idosos com peso adequado (IMC entre 22 e $27 \mathrm{~kg} / \mathrm{m}^{2}$ ), $42 \%$ com excesso de peso (IMC $\geq 27 \mathrm{~kg} / \mathrm{m}^{2}$ ) e $14 \%$ com baixo peso (IMC $\leq 22 \mathrm{~kg} / \mathrm{m}^{2}$ ) (BOLETIM ISA - CAPITAL 2008, 2011), e, por sua vez, utilizou critérios proposto pela Nutrition Screening Initiative (NSI) (NSI, 1994). 


\subsection{CONDIÇÕES BUCAIS}

A redução do número e da função dos dentes tem sido associada ao comprometimento do estado nutricional (SAVOCA et al., 2009), sem, no entanto, apresentar consenso na perda ou no ganho de peso, podendo levar idosos ao baixo ou ao excesso de peso, estando o excesso de peso associado à obesidade e doenças crônicas não transmissíveis (SILVEIRA et al., 2009), e o baixo peso, ao maior risco de óbito (OTERO et al., 2002).

A população idosa é particularmente vulnerável a restrições dietéticas, porque tende a ter menos dentes naturais, com possiveis consequências para o seu estado nutricional, como identificaram Marcenes et al. (2003), que constataram, em 949 idosos ( $\geq 65$ anos), participantes do British National Diet and Nutrition Survey (NDNS), no Reino Unido, que edêntulos totais têm significativamente mais chances de estarem com baixo peso do que aqueles com 11 dentes ou mais, enquanto indivíduos com menos de 21 dentes naturais têm risco 3 vezes maior de ser obesos do que os que tem de 21 a 32 dentes.

Na I Conferência Nacional de Saúde Bucal (BRASIL, 1986), as condições bucais adequadas foram definidas como parte integrante e inseparável da saúde dos indivíduos, merecendo atenção especial pelo fato de que, historicamente, os serviços odontológicos não apresentavam como prioridade, a assistência aos indivíduos com 60 anos ou mais, com altas prevalências de edentulismo total, de cárie e de doenças periodontais, sendo reconhecido que a condição bucal adequada é decisiva para a manutenção da boa qualidade de vida (BRASIL, 2004).

Um dos grandes desafios, na prática odontológica, é conseguir que as pessoas mantenham, ao longo da vida, o maior número possível de dentes naturais (NARVAI e ANTUNES, 2003), visto que o edentulismo ainda é aceito como situação natural com o avanço da idade, e não como reflexo da falta de políticas preventivas de saúde, destinadas, principalmente, à população adulta, para que 
mantenha seus dentes em boas condições até idades mais avançadas (ROSA et al., 1992; SHINKAI e CURY, 2000; PUCCA Jr, 1999).

Os idosos de hoje viveram em época na qual o edentulismo era considerado situação inevitável e, não, problema que merecia ou podia ser corrigido, causando incômodos, aparência indesejada, dificuldade mastigatória, problemas na fala e limitações nas relações sociais, que podem comprometer a qualidade de vida (SILVA e CASTELLANOS FERNANDES, 2001; MOREIRA et al., 2005; HAIKAL et al. 2011).

Em 2004, por determinação do então presidente da república Luiz Inácio Lula da Silva, o Ministério da Saúde lança a Política Nacional de Saúde Bucal Brasil Sorridente, que teve como embasamento epidemiológico a conclusão do Projeto SB Brasil 2003 - Levantamento Nacional das Condições de Saúde Bucal da População Brasileira, a maior pesquisa epidemiológica envolvendo idosos de 65 a 74 anos de 247 municípios brasileiros, totalizando 5.349 indivíduos avaliados em $2003 \mathrm{e}$ 7.509, em 2010, sete anos após o lançamento do Brasil Sorridente, concluindo o quarto levantamento epidemiológico de âmbito nacional na área de Saúde Bucal pelo Ministério da Saúde, intitulado SB BRASIL 2010 - Pesquisa Nacional de Saúde Bucal (BRASIL, 2005; BRASIL, 2011).

Uma das medidas avaliadas no Projeto SB Brasil foi o índice CPO-D (quantidade de dentes cariados, perdidos ou obturados), e na população de 65 a 74 anos foi de 27,53, com maior contribuição do componente perdido (Figura 7), (BRASIL, 2011), evidenciando ser comum a prática da extração de dentes nestes indivíduos no país. 
Figura 7. Média do CPO-D e respectivos componentes segundo grupo etário. Brasil, 2010.

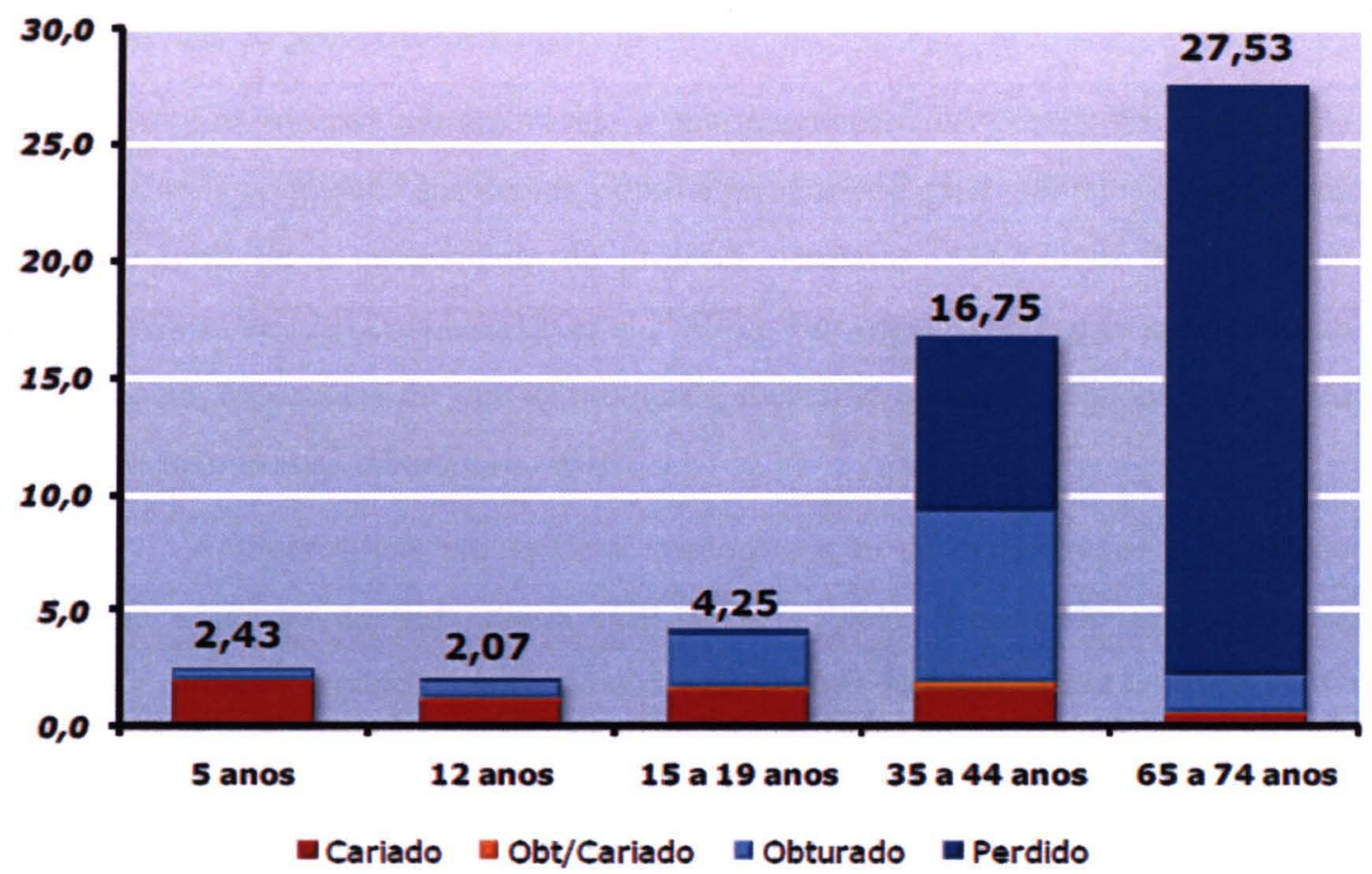

Fonte: BRASIL (2011).

Para Barbato et al. (2007), o edentulismo, ou a perda total dos dentes, é um dos piores agravos para a saúde bucal, sendo que no Brasil, é elevado o índice de edêntulos e a população idosa, economicamente menos favorecida, é a mais afetada possivelmente por depender do sistema de saúde público, com menos recursos e pouca informação.

Os estudos mostram como as condições bucais dos idosos são precárias, o que pode comprometer o estado nutricional, identificando-se maior risco para baixo peso em idosos que utilizavam próteses totais em ambos os arcos, comparados aqueles com dentes naturais (COUSSON et al., 2012).

No Brasil, as condições bucais da maioria da população idosa são insatisfatórias (SILVA, SOUSA e WADA, 2001), porque apresenta prevalências de problemas bucais: 55\% de edêntulos totais (MOREIRA et al., 2009), 59\% uma ou mais lesões da mucosa oral (COLUSSI e FREITAS, 2002), 80\% com necessidade de colocação ou substituição de próteses dentárias (SILVA e VALSECKI JR., 2000) e 
$63,1 \%$ de usuários de prótese total superior no país $(63,7 \%$ na região Sudeste $)$ e $37,5 \%$ de inferior para o Brasil (38\% no Sudeste), região considerada uma das mais desenvolvidas do país (BRASIL, 2011).

Em idosos, muitas vezes, a autopercepção das condições bucais não reflete as reais condições dos dentes, como a presença de cáries ou outras doenças na cavidade oral, ou a necessidade de próteses dentárias (MARTINS et al., 2010; COUSSON et al., 2012; HAIKAL et al., 2011). Em geral, os homens apresentaram piores condições bucais do que as mulheres, inclusive quando avaliados segundo a autopercepção (PATTUSSI et al., 2010).

Autopercepção em saúde é a interpretação de experiências e estado de saúde no contexto da vida diária (GILBERT, 1994), fornecendo uma maneira simples e direta de captar as percepções das condições de saúde, que é confiável e de baixo custo (LOCKER, 1996).

Existem escalas de questões subjetivas, pelas quais é possível de quantificar a qualidade de vida e as condições bucais percebidas (SILVA e SOUSA, 2006), como Dental Impact on Daily Living (DIDL) (LEÃO e SCHEIHAM, 1996), Oral Health-related Quality of Life Measure (OHQOL) (KRESSIN,1997), Oral Health Impact Profile (OHIP) (SLADE e SPENCER, 1994; SLADE, 1997) e Geriatric Oral Health Assessment Index (ATCHISON e DOLAN,1990).

Atchison e Dolan (1990) propuseram o Geriatric Oral Health Assessment Index (GOHAI), que é um método que permite a mensuração de condições bucais autorreferidas e o impacto na saúde bucal, nos últimos três meses, com uso de questionário, composto por 12 questões, que permite identificar como os idosos percebem suas condições bucais, podendo investigar problemas relacionados às condições bucais em três dimensões: física, psicossocial e dor/desconforto (ATCHISON e DOLAN, 1990; ATCHISON, 2007), utilizado tanto em estudos transversais como em longitudinais (HASSEL et al., 2011).

Cada alternativa de resposta das 12 questões recebe uma pontuação (de 1 a 5), podendo variar de 12 a 60 pontos. Os indivíduos com escore abaixo de 50 pontos são considerados com más condições bucais, de 51 a 56 pontos, condições 
bucais regulares e, de 57 a 60 pontos, pontuação máxima, boas condições bucais (ATCHISON e DOLAN, 1990).

Condições bucais mais prevalentes, como edentulismo e não uso de prótese dentária, podem causar um alto impacto, diminuindo a qualidade de vida dos indivíduos e limitando suas ações de vida diárias, comprometendo o estado nutricional, predispondo ao peso inadequado (baixo peso ou excesso de peso), incidindo mais com o avanço da idade, quando ocorre maior prevalência de edentulismo e procura por prótese (PETERSEN, 2003; MESAS et al., 2010; COUSSON et al., 2012).

$\mathrm{Na}$ tentativa de verificar essa relação, há estudos longitudinais e transversais, em sua maioria, que demonstram controvérsias, pois alguns autores encontraram associação entre condições bucais inadequadas (p. ex. edêntulos sem próteses; e condições regulares ou ruins, segundo a autopercepção), com maior risco para subnutrição (FINCH et al., 1998; HICKSON, 2006; DE MARCHI et al.; 2008; GIL-MONTOYA et al.; 2008; NASCIMENTO et al.; 2012), outros encontraram com maior risco para excesso de peso (BERNARDO et al., 2012; HILGERT et al., 2009; NASCIMENTO et al.; 2012), e teve aquele que não encontrou associação do estado nutricional com edentulismo parcial ou total e condições bucais (MESAS et al., 2010).

Há falta de consenso sobre a associação das condições bucais com alterações do estado nutricional de idosos ao longo dos anos, por serem escassos estudos epidemiológicos e de base populacional (NARVAI e ANTUNES, 2003), sendo mais comum encontrar na literatura estudos transversais, não adequados para verificar associação causal dessas alterações. Dessa forma, é mais difícil investigar as associações dessas condições no estado nutricional (PERISSINOTTO et al., 2002).

Existe lacuna no conhecimento sobre o papel das condições bucais, em termos de alterações no estado nutricional e, consequentemente, na qualidade de vida de idosos (MARCENES et al., 2003; ANDRADE et al., 2012a). 
Verificar a associação entre alterações do estado nutricional, perda dentária, uso de próteses e autopercepção das condições bucais referidas em uma coorte de idosos, domiciliados no município de São Paulo, segundo sexo e idade, em 2000 e 2006. 
3. Casuística e Métodos 


\subsection{DELINEAMENTO DO ESTUDO}

Trata-se de estudo epidemiológico, longitudinal, de base domiciliar, com utilização dos dados do Estudo SABE (Saúde, Bem-estar e Envelhecimento), realizado no município de São Paulo, em 2000 e 2006.

Em 2000, o Estudo SABE foi multicêntrico, epidemiológico, de base domiciliar, realizado em sete países da América Latina e Caribe (Argentina, Barbados, Brasil, Chile, Cuba, México e Uruguai), coordenado pela Organização Pan-Americana de Saúde (OPAS), visando avaliar as condições de vida e saúde, de idosos de 60 anos ou mais, de ambos os sexos (PELÁEZ et al., 2003).

No Brasil, foi realizado na área urbana do município de São Paulo, coordenado por docentes do Departamento de Epidemiologia da Faculdade de Saúde Pública da Universidade de São Paulo (FSP/USP), com financiamento da Fundação de Amparo à Pesquisa do Estado de São Paulo (FAPESP) e auxílio financeiro da Área Técnica do Idoso (ATI) do Ministério da Saúde (LEBRÃO e LAURENTI, 2005; LEBRÃO e DUARTE, 2008).

A amostra final de 2.143 idosos, de 60 anos ou mais, foi composta por dois segmentos: o primeiro, resultante de sorteio por amostragem probabilística, foi obtido nos domicílios, distribuídos em setores censitários, segundo zonas geográficas do município, e correspondeu a 1.568 idosos; o segundo foi composto por 575 idosos, correspondente ao acréscimo, efetuado para compensar a maior taxa de mortalidade da população igual ou maior de 75 anos, e menor densidade do sexo masculino, realizado através da localização de moradias próximas aos setores selecionados, ou no máximo, dentro dos limites dos distritos aos quais pertenciam os setores sorteados (SILVA, 2003). 
Os dados foram obtidos por meio de entrevistas realizadas por equipes previamente treinadas para realizá-las pelos pesquisadores responsáveis, e registrados em questionário específico, elaborado pela Organização Pan-Americana de Saúde (OPAS), traduzido e adaptado para o Brasil, composto por onze seções (LEBRÃO e LAURENTI, 2005), com destaque para as utilizadas neste estudo (Quadro 1).

Quadro 1. Seções do questionário, utilizadas no Estudo SABE, em 2000.

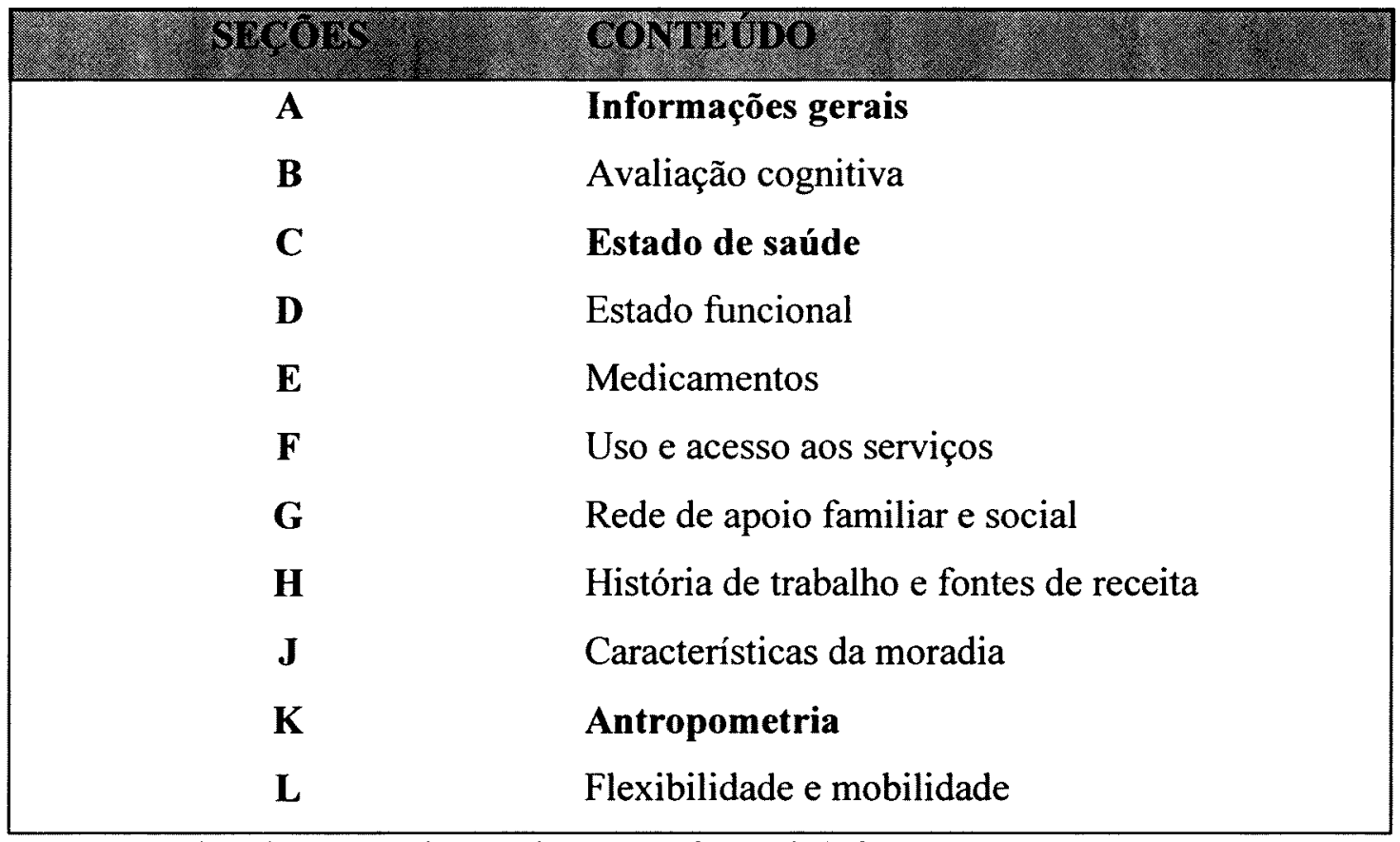

Fonte: Questionário SABE. Disponivel em: www.fsp.usp.br/sabe

Em 2006, o estudo foi transformado em coorte, pois foram reentrevistados os idosos sobreviventes de 2000, localizados, domiciliados no município e que concordaram em participar do estudo, com procedimentos para a coleta de dados semelhantes àqueles realizados anteriormente, financiados pela FAPESP (LEBRÃO e DUARTE, 2008). 
A coleta de dados abrangeu 1.115 idosos, sendo a diferença relacionada a óbitos (649), recusas (177), não localizados (139), mudanças para outros municípios (52) e institucionalizações (11).

\subsection{POPULAÇÃO DE ESTUDO}

A população deste estudo foi constituída por idosos, de ambos os sexos, sobreviventes de 2000, que foram localizados e concordaram em participar, em 2006, totalizando 1.115 indivíduos.

Foram incluídos, na amostra, idosos que apresentaram todos os dados necessários referentes às variáveis estudadas.

Os critérios de exclusão foram: idosos que não responderam (NR) ou não souberam (NS) informar sobre as condições bucais (ausência de dentes, uso de prótese e questões de percepção) e que não puderam ter peso e estatura mensurados.

Desta forma, a amostra final foi de 773 idosos, sendo $40 \%$ homens e $60 \%$ mulheres (Figura 8). 
Figura 8. Fluxograma de seleção da amostra deste estudo.

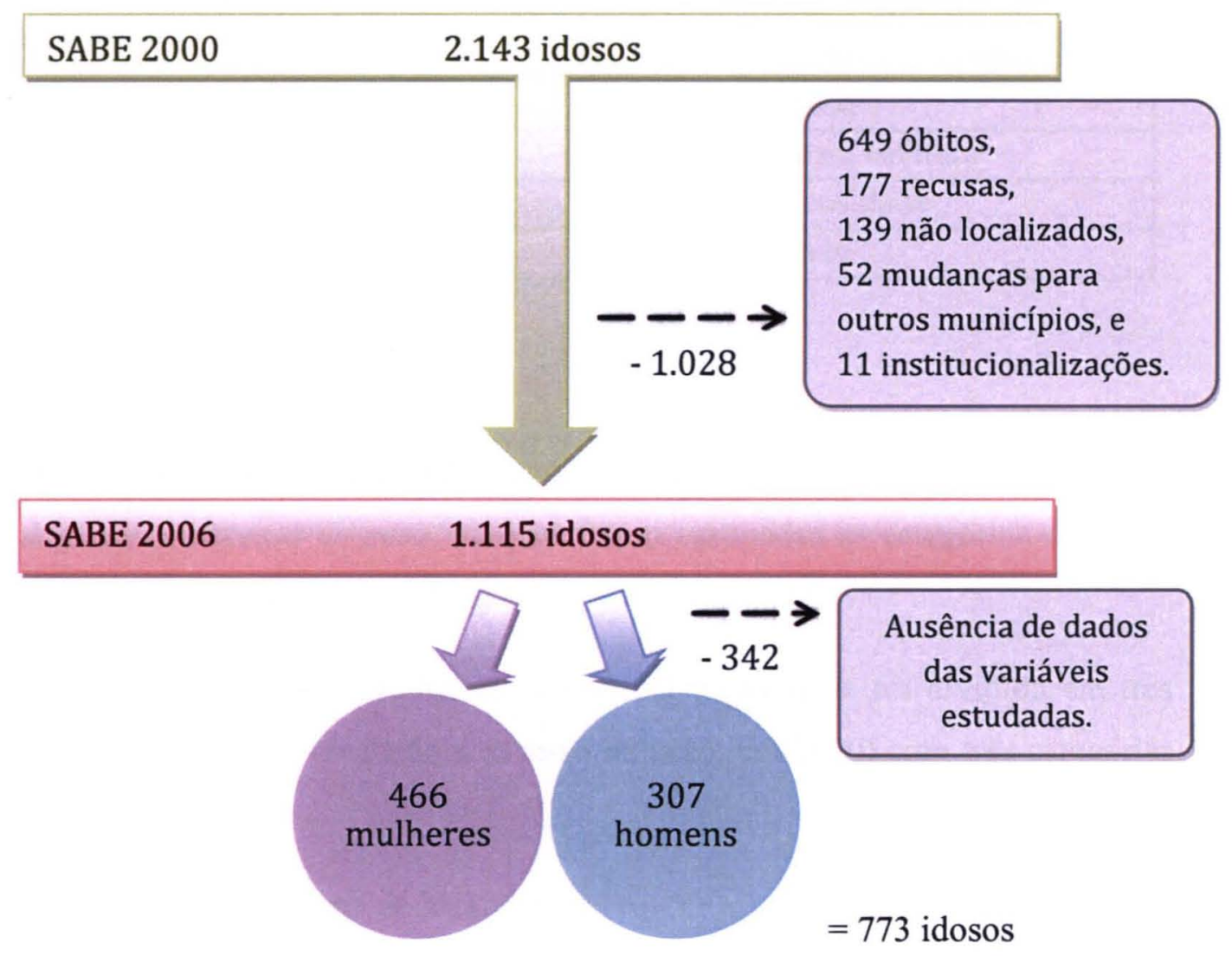

\subsection{VARIÁVEIS DE ESTUDO}

\subsubsection{Variável dependente}

3.3.1.1 Alterações no estado nutricional - identificado pelo diagnóstico do estado nutricional, obtido segundo cálculo do Índice de Massa Corporal (IMC), em 2000 e 2006, utilizando dados de peso (kg) e estatura (m).

Por não haver consenso nos valores de referência para classificação do estado nutricional em idosos (MURASCO e BERNSTEIN, 1998; HEIAT et al, 2001; INELMEN et al, 2000), a OPAS sugeriu valores de referência (OPAS, 2001) para o Estudo SABE, a ser adotado nos sete países participantes (PELÁEZ et al., 2003) (Quadro 2): 
Quadro 2. Classificação do estado nutricional dos idosos, segundo valores de IMC.

\begin{tabular}{|c|c|}
\hline Valores de IMC & Classificação do estado nutricional \\
\hline$\leq 23 \mathrm{~kg} / \mathrm{m}^{2}$ & Baixo peso \\
\hline$>23 \mathrm{e}<28 \mathrm{~kg} / \mathrm{m}^{2}$ & Peso adequado para estatura \\
\hline$\geq 28 \mathrm{e}<30 \mathrm{~kg} / \mathrm{m}^{2}$ & Risco para obesidade \\
\hline$\geq 30 \mathrm{~kg} / \mathrm{m}^{2}$ & Obesidade \\
\hline
\end{tabular}

Fonte: OPAS (2001).

Foram consideradas três categorias de estado nutricional: baixo peso, peso adequado e excesso de peso, na qual foram agrupadas as categorias de 'risco para obesidade' e 'obesidade' $\left(\geq 28 \mathrm{~kg} / \mathrm{m}^{2}\right)$.

Para as análises estatísticas, a variável dependente foi dividida em três grupos (baixo peso, peso adequado e excesso de peso, em 2000) com três categorias cada (Figura 9):

Exemplo no grupo de baixo peso:

- sem alteração - baixo peso em 2000 e em 2006,

- baixo peso em 2000 e peso adequado em 2006, e

- baixo peso em 2000 e excesso de peso em 2006.

Figura 9. Algoritmo para o desenho deste estudo.

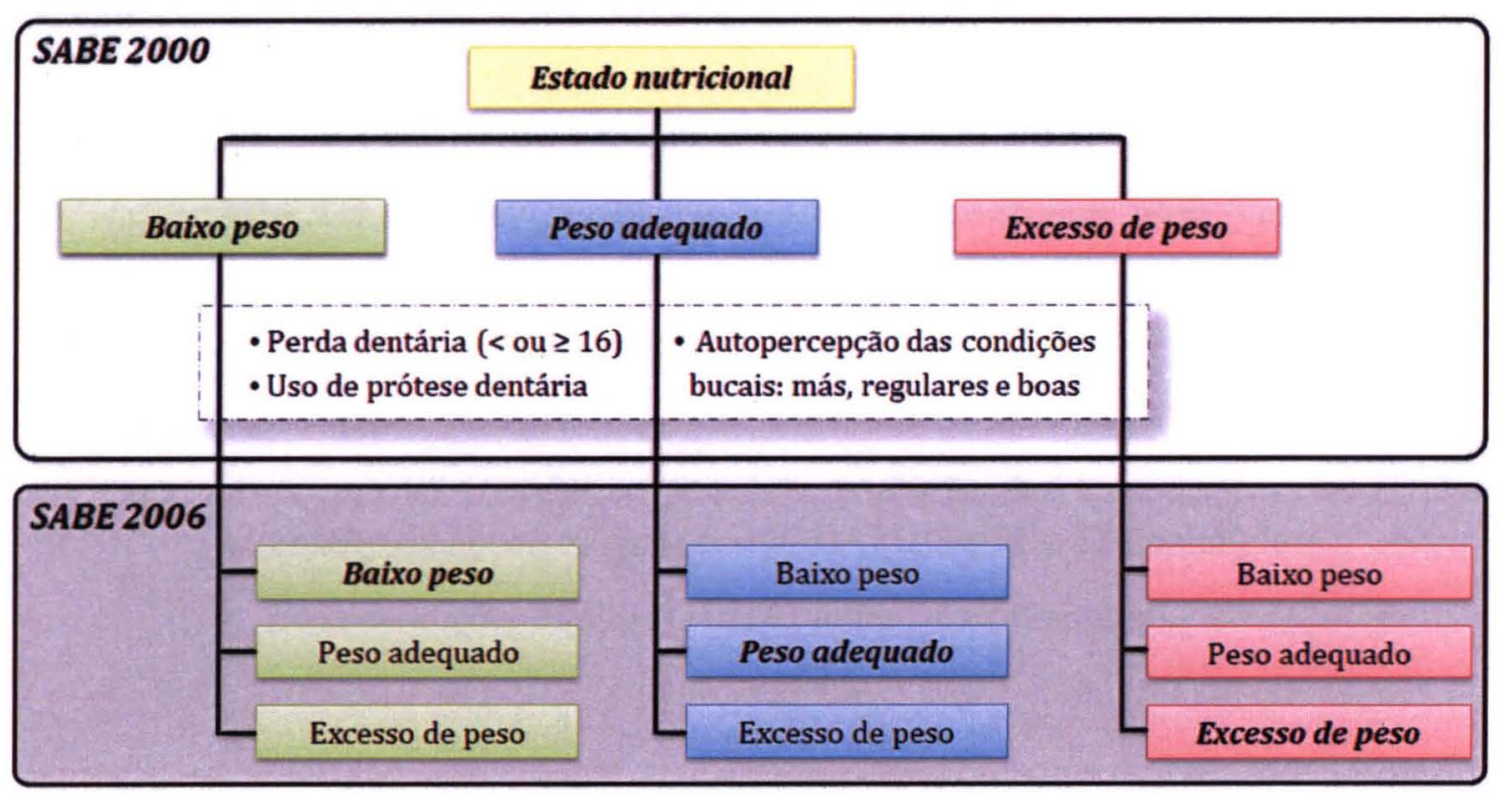


3.3.2 Variáveis independentes

\subsubsection{Variáveis de interesse}

3.2.2.1.1 Perda dentária referida, em 2000 - de acordo com os dados da questão C16, da seção C - Estado de Saúde, onde se observa a seguinte pergunta: "Agora passaremos a falar da boca e dos seus dentes. Faltam-lhe alguns dentes?". As opções de resposta foram divididas em duas categorias: perda menor que 16 ou de 16 dentes ou mais (Quadro 3).

Quadro 3. Categorização da perda dentária.

\begin{tabular}{|l|l|}
\hline \multicolumn{2}{|c|}{ Categorização da perda dentária } \\
\hline - Sim, uns poucos (até 4) & $\geq 16$ dos dentes \\
- Sim, bastante (mais de 4 e menos da metade) & \\
- Não & \\
\hline
\end{tabular}

3.2.2.1.2 Uso de prótese dentária, em 2000 - se usa ou não prótese dentária, ponte, dentadura ou dentes postiços.

3.2.2.1.3 Autopercepção das condições bucais, em 2000 - identificada pelo Geriatric Oral Health Assessment Index (GOHAI). Os idosos foram agrupados em três categorias (ATCHISON e DOLAN, 1990).

- más condições bucais (GOHAI $<50$ pontos);

- condições bucais regulares (GOHAI entre 51 e 57 pontos); e

- boas condições bucais (GOHAI entre 51 e 60 pontos). 


\subsubsection{Variáveis de controle}

\subsection{Sexo}

- masculino

- feminino

\subsection{Grupos etários, em 2000}

- 60 a 74 anos

- $\geq 75$ anos

\subsection{ANÁLISES ESTATÍSTICAS}

Como a população deste estudo resultou de amostras complexas, utilizaram-se testes e análises estatísticas indicados para estudos tipo survey ("svy").

Para a estatística descritiva, caracterizou-se a população, por meio de frequências relativas (\%) de idosos, para todas as variáveis (alterações no estado nutricional, no período de 2000 a 2006; perda dentária, uso de prótese e autopercepção das condições bucais, em 2000), segundo as variáveis de controle.

Para verificar a associação entre a variável dependente $\mathrm{e}$ as independentes, inicialmente, utilizou-se o teste de qui-quadrado Rao-Scott (RAO e SCOTT, 1984), sugerido para análises com dados de amostra complexa, com nível de significância estabelecido em $5 \%(\mathrm{p}<0,05)$.

A magnitude da associação foi calculada utilizando análise de regressão multinomial, adequada para casos em que a variável dependente tem como resposta mais de duas categorias nominais, no caso, três: baixo peso, peso adequado e excesso de peso, sendo possível verificar a associação entre cada categoria de estado 
nutricional em 2000, isoladamente, com as demais categorias do estado nutricional em 2006, e possíveis associações dessa alteração com as variáveis independentes (perda dentária, uso de prótese e autopercepção das condições bucais), ilustrado na figura 7 (pág. 36).

A regressão logística multinomial foi realizada, inicialmente por meio da análise univariada multinomial, no qual se verificou associação do estado nutricional com cada uma das variáveis independentes, quando $p<0,20$, na univariada, selecionadas e inseridas em ordem crescente no modelo final de regressão multinomial múltipla, permanecendo aquelas que apresentaram $p<0,05$.

A medida da magnitude de efeito foi verificada pelos valores de Risco Relativo (RR) e respectivos intervalos de confiança (IC95\%).

As variáveis independentes foram categorizadas sem risco (valor 0) e com risco (valor 1), sendo consideradas com risco: sexo masculino, grupo etário com 75 anos ou mais, ausência $\geq 16$ dentes; não uso de prótese e más condições bucais.

O software STATA 10.1 (StataCorp., College Station, $T X$ ) foi utilizado para as análises estatísticas e a correção do desenho da análise foi realizada com o comando survey (svy), para dados originários de amostras complexas.

\subsection{ASPECTOS ÉTICOS}

O Estudo SABE 2000 foi aprovado pelo Comitê de Ética em Pesquisa da Faculdade de Saúde Pública da Universidade de São Paulo (COEP) (ANEXO I) e pela Comissão Nacional de Ética em Pesquisa (CONEP) (ANEXO II). Em 2006, pelo COEP (ANEXO III).

Esta pesquisa foi aprovada pelo Comitê de Ética em Pesquisa (CEP) da Faculdade de Saúde Pública da Universidade de São Paulo, tendo início após a aprovação desse órgão (ANEXO IV) e após a autorização para utilização dos dados pela responsável pelo Estudo SABE no Brasil, em 2012 (ANEXO V). 
Da amostra de idosos analisada, 60\% eram mulheres e $80,55 \%$ apresentaram, em 2000, 60 a 74 anos.

Analisando perda dentária, 77,53\% referiram perda de 16 dentes ou mais, em 2000. Em relação ao grupo etário, dentre aqueles de 60 e 74 anos, 74,69\% referiram perda $\geq 16$ dentes, enquanto, em $\geq 75$ anos, essa prevalência foi maior $(89,31 \%)$. Dos homens, $73,68 \%$ referiram perda $\geq 16$ dentes, enquanto nas mulheres, esse percentual foi maior $(84,06 \%)$ (Tabela 1$)$.

Tabela 1. Distribuição da proporção dos idosos segundo variáveis independentes, sexo e grupos etários. Estudo SABE, São Paulo/Brasil, 2000.

\begin{tabular}{lccccc}
\hline & \multicolumn{2}{c}{ Sexo } & \multicolumn{2}{c}{ Grupos etários } & \\
& Feminino & Masculino & 60-74 anos & $\geq \mathbf{7 5}$ anos & Total \\
\hline Perda dentária & $\%$ & $\%$ & $\%$ & $\%$ & $\%$ \\
\hline 16 dentes & 19,89 & 26,32 & 25,31 & 10,69 & $\mathbf{2 2 , 4 7}$ \\
$\geq 16$ dentes & 80,11 & 73,68 & 74,69 & $89,31^{\dagger}$ & $\mathbf{7 7 , 5 3}$ \\
\hline Uso de prótese & & & & & \\
\hline Sim & 86,46 & 74,7 & 82,47 & 81,6 & $\mathbf{8 1 , 7 7}$ \\
Não & 13,54 & $25,3^{\dagger}$ & 17,53 & 18,4 & $\mathbf{1 8 , 2 3}$ \\
Condiçöes bucais & & & & & \\
\hline Boas & 51,36 & 57,26 & 50,58 & 54,48 & $\mathbf{5 3 , 7 2}$ \\
Regulares & 25,91 & 22,04 & 29,01 & 23,23 & $\mathbf{2 4 , 3 6}$ \\
Más & 22,73 & 20,7 & 20,42 & 22,28 & $\mathbf{2 1 , 9 2}$ \\
\hline
\end{tabular}

Legenda: ${ }^{1}$ Condições bucais segundo a autopercepção. ${ }^{\dagger} p<0,05$. Fonte: SABE, 2000.

Em relação ao uso de prótese dentária, $81,77 \%$ dos idosos referiram usar algum tipo de prótese dentária (parcial ou total). Analisando por sexo, 74,7\% homens e $86,46 \%$ mulheres referiram usar prótese, enquanto, por grupo etário, $81,6 \%$ tinham de 60 a 74 anos e, $82,47 \%, \geq 75$ anos (Tabela 1 ).

Uma vez definido o Geriatric Oral Health Assessment Index (GOHAI) dos idosos, foi encontrado escore médio de 54,51 (DP 6,99), classificando os idosos 
com condições bucais regulares, situação de $25,91 \%$. A maioria $(53,72 \%)$ apresentou boas condições bucais. Por sexo, 51,36\% das mulheres e 57,26\% dos homens referiram ter boas condições bucais. Segundo grupo etário, 50,58\% de 60 a 74 anos, e $54,48 \%$ de $\geq 75$ anos, referiram ter boas condições bucais, segundo a autopercepção (Tabela 1).

Analisando a associação, por meio do teste Rao-Scott, entre a variável dependente (estado nutricional) e as independentes, pode-se verificar associação apenas entre as variáveis de controle: sexo, em 2000 e 2006; e grupos etários, apenas em 2006 (Tabela 2).

Tabela 2. Associação do estado nutricional dos idosos em 2000 e 2006 e variáveis independentes. Estudo SABE, São Paulo/Brasil, 2000-2006.

\begin{tabular}{lcccccccc}
\hline & \multicolumn{3}{c}{ Estado nutricional em 2000 } & \multicolumn{3}{c}{ Estado nutricional em 2006 } \\
& BP (\%) & PA (\%) & EP (\%) & $P$ & BP (\%) & PA (\%) & EP (\%) & $p$ \\
\hline Perda dentária & & & & & & & & \\
\hline$<16$ dentes & 16,09 & 43,34 & 40,57 & 0,7278 & 29,35 & 42,26 & 28,39 & 0,6980 \\
$\geq 16$ dentes & 16,29 & 47,46 & 36,28 & & 25,54 & 45,33 & 29,13 & \\
\hline Uso de prótese & & & & & & & & \\
Sim & 14,98 & 47,69 & 37,33 & 0,5354 & 25,94 & 43,98 & 30,08 & 0,5686 \\
Não & 19,30 & 42,26 & 38,44 & & 28,01 & 47,23 & 24,77 & \\
Condições bucais ${ }^{\prime}$ & & & & & & & & \\
Boas & 15,55 & 46,89 & 37,55 & 0,8706 & 26,93 & 43,19 & 29,88 & 0,5686 \\
Regulares & 19,57 & 45,25 & 35,18 & & 23,01 & 45,72 & 31,27 & \\
Más & 14,55 & 47,01 & 38,44 & & 28,27 & 46,88 & 24,85 & \\
Sexo & & & & & & & & \\
Masculino & 21,45 & 57,43 & 21,12 & $\mathbf{0 , 0 0 0 0}$ & 28,07 & 53,22 & 18,71 & $\mathbf{0 , 0 0 0 1}$ \\
Feminino & 12,90 & 39,64 & 47,46 & & 25,38 & 39,43 & 35,19 & \\
Grupos Etários & & & & & & & & \\
60 a 74 anos & 15,34 & 46,87 & 37,78 & $\mathbf{0 , 3 6 4 6}$ & 19,02 & 46,54 & 34,43 & $\mathbf{0 , 0 0 4 7}$ \\
$\geq 75$ anos & 19,75 & 45,23 & 35,02 & & 30,74 & 43,52 & 25,74 & \\
Total & $\mathbf{1 6 , 2 2}$ & $\mathbf{4 6 , 5 5}$ & $\mathbf{3 7 , 2 3}$ & & $\mathbf{2 6 , 4}$ & $\mathbf{4 4 , 6 4}$ & $\mathbf{2 8 , 9 6}$ & \\
\hline
\end{tabular}

Legenda: BP - baixo peso; PA - peso adequado; EP - excesso de peso. ${ }^{1}$ Condições bucais segundo a autopercepção. Fonte: SABE, 2000-2006.

Em 2000, verificou-se prevalência de $16,22 \%$ com baixo peso, $46,55 \%$, peso adequado para estatura, e 37,23\%, excesso de peso. Segundo sexo, observaramse menores prevalências de baixo peso nas mulheres $(12,90 \%)$, quando comparadas 
aos homens $(21,45 \%)$, enquanto, com excesso de peso, a prevalência de mulheres $(47,46 \%)$ foi mais do que o dobro dos homens $(21,12 \%)$.

Por grupos etários, a prevalência de baixo peso no grupo de 60 a 74 anos $(15,34 \%)$ foi menor, quando comparada aos $\geq 75$ anos $(19,75 \%)$, enquanto, com excesso de peso, as prevalências foram semelhantes $37,78 \%$ e 35,02\%, respectivamente, para os grupos de 60 a 74 anos e $\geq 75$ anos (Tabela 2).

Observa-se, em 2006, diminuição da proporção de idosos com excesso de peso e aumento da proporção daqueles com baixo peso, resultando em $28,96 \%$ e $26,4 \%$, respectivamente (Tabela 2 ).

Quanto à proporção de idosos com baixo peso, em ambos os sexos, houve aumento, passando de 21,45 para $28,07 \%$ nos homens e de 12,90 para $25,38 \%$ nas mulheres, enquanto com excesso de peso, houve diminuição de 21,12 para 18,71\% nos homens e de 47,46 para 35,19\% nas mulheres (Tabela 2).

Segundo grupo etário, a proporção de idosos com baixo peso foi $19,02 \%$, 60 a 74 anos e, 30,74\%, $\geq 75$ anos, superiores quando comparadas com as prevalências de 2000 (Tabela 2).

Daqueles com peso adequado para estatura, 46,54\% tinham entre 60 e 74 anos e 43,52\%, $\geq 75$ anos, enquanto, naqueles com excesso de peso, as proporções foram menores às de 2000 , sendo $34,43 \%$, de 60 a 74 anos e, 25,74\%, $\geq 75$ anos (Tabela 2).

Dos idosos com baixo peso em 2000, verificou-se em 2006, menor risco para peso adequado $[R R=0,35(0,08-1,46)]$ aqueles idosos com perda $\geq 16$ dentes; $\mathrm{e}$ para excesso de peso $[R R=0,31(0,07-1,43)]$, nos idosos com más condições bucais (Tabela 3). 
Tabela 3. Associação entre estado nutricional em 2006, e as variáveis independentes, segundo risco relativo, dos idosos com baixo peso ${ }^{1}$ em 2000. Estudo SABE, São Paulo/Brasil, 2000-2006.

\begin{tabular}{lcc}
\hline Variáveis independentes & $\begin{array}{c}\boldsymbol{B P 2 0 0 0 - P A 2 0 0 6} \\
\boldsymbol{R} \boldsymbol{R}(\boldsymbol{I C 9 5 \% )}\end{array}$ & $\begin{array}{c}\boldsymbol{B P 2 0 0 0 - E P 2 0 0 6} \\
\boldsymbol{R} \boldsymbol{R}(\boldsymbol{I C 9 5 \% )}\end{array}$ \\
\hline Perda $\geq 16$ dentes & $1,09(1,87-6,38)$ & $0,35(0,08-1,46)^{\dagger}$ \\
Não uso de prótese & $2,15(0,61-7,49)$ & $1,28(0,35-4,67)$ \\
Condições bucais regulares & $1,30(0,27-6,37)$ & $2,24(0,48-10,48)$ \\
Más condições bucais & $0,96(0,27-3,38)$ & $0,31(0,07-1,43)^{+}$ \\
Sexo Masculino & $0,87(0,35-2,12)$ & $0,65(0,25-1,71)$ \\
Grupo $\geq 75$ anos & $0,78(0,36-1,72)$ & $1,02(0,44-2,36)$ \\
\hline
\end{tabular}

Legenda: BP2000 - baixo peso em 2000; PA2006 - peso adequado em 2006; EP2006 - excesso de peso em 2006. RR - risco relativo; IC95\% - intervalo de confiança em $95 \%$.

'Baixo peso em 2000 e em 2006 (sem alteração) = categoria de referência.

' $\mathrm{p}<0,20$ (selecionadas para a análise de regressão multinomial múltipla).

Nota: As variáveis omitidas foram: grupo entre 60 e 74 anos; sexo feminino; perda $<16$ dentes; uso de prótese; e boas condições bucais.

Fonte: SABE 2000-2006.

$\mathrm{Na}$ regressão multinomial múltipla, foram inseridas as variáveis que apresentaram $p<0,20$ na univariada. Não se constatou associação para excesso de peso, em 2006 (Tabela 4).

Tabela 4. Associação entre estado nutricional em 2006, e as variáveis sexo e grupos etários, segundo risco relativo, dos idosos com baixo peso ${ }^{1}$ em 2000 . Estudo SABE, São Paulo/Brasil, 2000-2006.

\begin{tabular}{lcc}
\hline Variáveis independentes & $\boldsymbol{B P 2 0 0 0 - P A 2 0 0 6}$ & $\boldsymbol{B P 2 0 0 0 - E P 2 0 0 6}$ \\
& $\boldsymbol{R} \boldsymbol{R}(\boldsymbol{I C 9 5 \% )}$ & $\boldsymbol{R} \boldsymbol{R}(\boldsymbol{I C 9 5 \% )}$ \\
\hline Perda $\geq 16$ dentes & $1,10(0,18-6,72)$ & $0,24(0,05-1,12)$ \\
Más condições bucais & $0,96(0,27-3,38)$ & $0,32(0,06-1,60)$ \\
\hline
\end{tabular}

Legenda: BP2000 - baixo peso em 2000; PA2006 - peso adequado em 2006; EP2006 - excesso de peso em 2006. RR - risco relativo; IC95\% - intervalo de confiança em $95 \%$.

'Baixo peso em 2000 e em 2006 (sem alteração) = categoria de referência.

Nota: As variáveis omitidas foram: condições bucais regulares e boas e perda $<16$ dentes.

Fonte: SABE 2000-2006.

Daqueles com peso adequado em 2000, observou-se associação indireta para excesso de peso em 2006, naqueles com condições bucais regulares [ $R R=0,31$ $(0,14-0,69)]$, do sexo masculino $[R R=0,24(0,12-0,46)] \mathrm{e} \geq 75 \operatorname{anos}[\mathrm{RR}=0,46$ $(0,26-0,81)]$ (Tabela 5). 
Tabela 5. Associação entre estado nutricional em 2006, e as variáveis, segundo risco relativo, dos idosos com peso adequado' ${ }^{2}$ em 2000. Estudo SABE, São Paulo/Brasil, 2000-2006.

\begin{tabular}{lcc}
\hline Variáveis independentes & $\begin{array}{c}\boldsymbol{P A 2 0 0 0 - B P 2 0 0 6} \\
\boldsymbol{R} \boldsymbol{R}(\text { IC95\%) }\end{array}$ & $\begin{array}{c}\boldsymbol{P A 2 0 0 0 - E P 2 0 0 6} \\
\boldsymbol{R R}(\boldsymbol{I C 9 5 \% )}\end{array}$ \\
\hline Perda $\geq 16$ dentes & $0,86(0,40-1,82)$ & $1,46(0,65-3,27)$ \\
Não uso de prótese & $1,05(0,50-2,21)$ & $0,84(0,38-1,85)$ \\
Condições bucais regulares & $\mathbf{0 , 7 2 ( 0 , 3 2 - 1 , 5 8 )}$ & $0,31(0,14-0,69)^{\dagger}$ \\
Más condições bucais & $1,65(0,75-3,63)$ & $1,65(0,75-3,63)$ \\
Sexo Masculino & $0,91(0,50-1,63)$ & $0,24(0,13-0,46)^{\dagger}$ \\
Grupo $\geq 75$ anos & $1,27(0,67-2,42)$ & $0,46(0,26-0,81)^{\dagger}$ \\
\hline
\end{tabular}

Legenda: PA2000 - peso adequado em 2000; BP2006 - baixo peso em 2006; EP2006 - excesso de peso em 2006. RR - risco relativo; IC95\% - intervalo de confiança em 95\%.

'Peso adequado em 2000 e em 2006 (sem alteração) = categoria de referência.

${ }^{\dagger} \mathrm{p}<0,20$ (selecionadas para a análise de regressão multinomial múltipla).

Nota: As variáveis omitidas foram: grupo entre 60 e 74 anos; sexo feminino; perda $<16$ dentes; uso de prótese; e boas condições bucais.

Fonte: SABE 2000-2006.

$\mathrm{Na}$ regressão multinomial múltipla, foram inseridas as variáveis que apresentaram $p<0,20$, na regressão multinomial univariada, manteve-se a associação indireta para excesso de peso, em 2006, naquele grupo de idosos com condições bucais regulares $[R R=0,31(0,14-0,68)]$ (Tabela 6).

Tabela 6. Associação entre estado nutricional, em 2006, e as variáveis sexo e grupos etários, segundo risco relativo, dos idosos com peso adequado ${ }^{1}$, em 2000. Estudo SABE, São Paulo/Brasil, 2000-2006.

\begin{tabular}{lcc}
\hline Variáveis independentes & $\boldsymbol{P A 2 0 0 0 - B P 2 0 0 6}$ & $\boldsymbol{P A 2 0 0 0 - E P 2 0 0 6}$ \\
& $\boldsymbol{R} \boldsymbol{R}(\mathbf{I C 9 5 \% )}$ & $\boldsymbol{R} \boldsymbol{R}(\boldsymbol{I C 9 5 \% )}$ \\
\hline Sexo masculino & $\mathbf{0 , 8 7}(0,46-1,62)$ & $0,22(0,38-1,41)$ \\
Condições bucais regulares & $\mathbf{0 , 7 0}(0,31-1,57)$ & $0,31(0,14-0,68)^{\S}$ \\
Grupo $\geq 75$ anos & $\mathbf{0 , 6 2}(0,34-1,12)$ & $0,60(0,32-1,10)$ \\
\hline
\end{tabular}

Legenda: PA2000 - peso adequado em 2000; BP2006 - baixo peso em 2006; EP2006 - excesso de peso em 2006. RR - risco relativo; IC $95 \%$ - intervalo de confiança em $95 \% .{ }^{\S} \mathrm{p}<0,05$.

${ }^{1}$ Peso adequado em 2000 e em 2006 (sem alteração) = categoria de referência.

Nota: As variáveis omitidas foram: sexo feminino, más e boas condições bucais e grupo etário entre 60 e 74 anos.

Fonte: SABE 2000-2006. 
Daqueles com excesso de peso, em 2000, observou-se associação direta, em 2006, para baixo peso $[R R=2,28(1,07-4,85)]$ e para peso adequado $[R R=2,33$ $(1,21-4,49)]$, no sexo masculino, e indireta para baixo peso $[R R=0,29(0,08-1,05)]$, naqueles com más condições bucais (Tabela 7).

Tabela 7. Associação entre estado nutricional, em 2006, e as variáveis independentes, segundo risco relativo, dos idosos com excesso de peso', em 2000. Estudo SABE, São Paulo/Brasil, 2000-2006.

\begin{tabular}{lcc}
\hline Variáveis independentes & $\begin{array}{c}\text { EP2000-BP2006 } \\
\boldsymbol{R R}(\boldsymbol{I C 9 5 \%})\end{array}$ & $\begin{array}{c}\boldsymbol{E P 2 0 0 0 - P A 2 0 0 6} \\
\boldsymbol{R R}(\boldsymbol{I C 9 5 \%})\end{array}$ \\
\hline Perda $\geq 16$ dentes & $0,69(0,29-1,65)$ & $0,72(0,33-1,56)$ \\
Não uso de prótese & $1,45(0,60-3,52)$ & $1,21(0,55-2,69)$ \\
Condições bucais regulares & $1,23(0,52-2,92)$ & $1,25(0,56-2,80)$ \\
Más condições bucais & $0,29(0,08-1,05)^{\dagger}$ & $1,67(0,74-3,83)$ \\
Sexo Masculino & $2,28(1,07-4,85)^{\dagger}$ & $2,33(1,21-4,49)^{\dagger}$ \\
Grupo $\geq 75$ anos & $1,09(0,54-2,17)$ & $1,04(0,59-1,86)$ \\
\hline Legenda: EP2000 - excesso de peso em 2000; BP2006 - baixo peso em 2006; PA2006 - peso \\
adequado em 2006. RR - risco relativo; IC95\% - intervalo de confiança em 95\%. \\
'Excesso de peso em 2000 e em 2006 (sem alteração) = categoria de referência. \\
'p < 0,20 (selecionadas para a análise de regressão multinomial múltipla). \\
Nota: As variáveis omitidas foram: grupo entre 60 e 74 anos; sexo feminino; perda < 16 dentes; uso \\
de prótese; e boas condiçoses bucais. \\
Fonte: SABE 2000-2006.
\end{tabular}

$\mathrm{Na}$ regressão multinomial múltipla, foram inseridas as variáveis que apresentaram $p<0,20$, na univariada, manteve-se a associação direta para peso adequado, em 2006, no sexo masculino $[R R=2,23(1,09-4,55)]$ (Tabela 8).

Tabela 8. Associação entre estado nutricional, em 2006, e as variáveis sexo e grupos etários, segundo risco relativo, dos idosos com excesso de peso', em 2000. Estudo SABE, São Paulo/Brasil, 2000-2006.

\begin{tabular}{lcc}
\hline Variáveis independentes & $\begin{array}{c}\boldsymbol{E P 2 0 0 0 - B P 2 0 0 6} \\
\boldsymbol{R} \boldsymbol{R}(\boldsymbol{I C 9 5 \% )}\end{array}$ & $\begin{array}{c}\boldsymbol{E P 2 0 0 0 - P A 2 0 0 6} \\
\boldsymbol{R} \boldsymbol{R}(\boldsymbol{I C 9 5 \% )}\end{array}$ \\
\hline Más condições bucais & $0,30(0,09-1,07)$ & $1,71(0,73-3,95)$ \\
Sexo masculino & $1,93(0,86-4,35)$ & $2,23(1,09-4,55)^{\xi}$ \\
\hline Legenda: EP2000 - excesso de peso em $2000 ;$ BP2006 - baixo peso em $2006 ;$ PA2006 - peso \\
adequado em 2006. RR - risco relativo; IC95\% - intervalo de confiança em $95 \%{ }^{8} \mathrm{p}<0,05$. \\
'Excesso de peso em 2000 e em 2006 (sem alteração) = categoria de referência. \\
Nota: As variáveis omitidas foram: sexo feminino e condições bucais regulares e boas. \\
Fonte: SABE 2000-2006.
\end{tabular}


5. Discussão 
Este estudo é de grande relevância por ser longitudinal, realizado com idosos ( $\geq 60$ anos) de ambos os sexos, domiciliados, que verificou associação entre estado nutricional, condições bucais (perde dentária e uso de prótese) e autopercepção das condições bucais, segundo o GOHAI, permitindo identificar relações causais, apesar da possibilidade de apresentar viéses, pela falta de controle de características importantes: medidas autoreferidas de condições bucais e tamanho da amostra dentro das categorias apresentadas.

A amostra estudada teve $59,95 \%$ de mulheres, concordando com dados do IBGE (2010), nos quais a proporção de idosas brasileiras $(55,5 \%)$ é superior à proporção de homens idosos $(44,5 \%)$.

A maior prevalência de idosos do grupo etário de 60 a 74 anos $(80,55 \%)$ presentes neste estudo é evidência da maior taxa de mortalidade em idosos mais velhos (WHO, 2002; CABRERA et al., 2007), pois, dos sobreviventes, a maioria tinha de 60 a 64 anos, em 2000.

A prevalência de $77,53 \%$ de idosos com perda $\geq 16$ dentes mostra situação precária nas condições bucais, semelhante aos dados da maior pesquisa epidemiológica nacional, Projeto Saúde Bucal Brasil (BRASIL, 2004), no qual foram entrevistados 5.349 indivíduos, de 65 a 74 anos, em 247 municípios brasileiros, verificando-se $60,9 \%$ com perdas dentárias entre 28 e 32 dentes, sendo $55 \%$ com edentulismo total, condição não foi avaliada neste estudo (MOREIRA et al., 2009; DIAS-DA-COSTA et al., 2010; MARTINS et al., 2008).

Ainda em relação à perda dentária, em Florianópolis/SC, na região sul do Brasil, Benedetti et al. (2007), no estudo "Perfil do Idoso do Município de Florianópolis" (2004) analisaram 875 idosos ( $\geq 60$ anos) e constataram que $66 \%$ referiram perda da maioria dos dentes, prevalência inferior àquela dos idosos deste trabalho $(77,53 \%)$, ainda que utilizando o mesmo critério para perda dentária (metade ou mais) e idade ( $\geq 60$ anos). 
Andrade et al. (2012a) revelaram que 25,64\% dos idosos participantes do SABE 2006 referiram más condições bucais, e esse percentual foi maior em indivíduos dentados $(30,45 \%)$ do que em edêntulos $(20,54 \%)$, evidenciando que idosos edêntulos estão conformados com suas condições bucais, situação natural aceita com o envelhecimento (ROSA et al., 1992), o que impede a procura por prevenção, tratamento ou melhores cuidados, pois não há a necessidade percebida pelos idosos, e pela mutilação dentária (retirada de todos os dentes) não corresponder à autopercepção negativa das condições bucais (NARVAI e ANTUNES, 2003), já que a situação de edêntulos totais pode remeter a adoção de próteses totais, representando uma melhoria na condição bucal (ATCHISON e GIFT; 1997).

Cardoso et al. (2011) identificaram, em 667 idosos (65 a 74 anos), na população de Manaus/AM, índice de dentes cariados, perdidos e obturados (CPO-D) igual a 29 (DP 4,3), com predomínio do componente perdido (95\%), média de 4,1 (DP 5,7) dentes por indivíduo, 52,2\% edêntulos totais e apenas 3\% com 20 dentes ou mais, situação diferente deste estudo que entrevistou indivíduos da região sudeste do país, podendo ter características socioeconômicas e demográficas diferentes por ser tratar de outra região do país.

A prevalência de $81,77 \%$ dos idosos usando algum tipo de prótese dentária (parcial superior ou inferior ou total) pode ser comparada ao estudo de Benedetti et al. (2007), no qual $75,1 \%$ de idosos ( $\geq 60$ anos), de Florianópolis/SC, relataram usar algum tipo de prótese dentária (parcial ou total), sendo que essas condições bucais comprometiam a mastigação em 19,8\% dos idosos, mas 80,2\% referiram já estar acostumados com a situação, pois adaptaram sua dieta, preparando alimentos menos consistentes.

Dados nacionais (MOREIRA et al., 2009; DIAS-DA-COSTA et al., 2010), em relação ao uso de prótese total, mostraram que $67 \%$ já usavam algum tipo de prótese, no arco superior, e $43 \%$, no inferior, prevalências menores ao deste estudo, que encontrou $81,77 \%$ provavelmente por abranger apenas o grupo etário de 65 a 74, não incluindo idosos com idade superior a 74 anos, podendo ter características peculiares por se tratar de idosos jovens. 
É possível encontrar estudos em todas as regiões geográficas do Brasil, apresentando resultados semelhantes quanto às condições bucais, apesar de serem poucos os de caráter longitudinal, de base populacional, com idosos domiciliados, em amostras representativas (SILVA et al., 2011).

Em São Paulo/SP, com dados do Estudo SABE 2000, Teixeira (2007) avaliou uma amostra de 1.212 idosos ( $\geq 65$ anos), e identificou $74,5 \%$ das mulheres e $53,4 \%$ dos homens usando prótese total na arcada superior, e $45,5 \%$ e $33,8 \%$, na arcada inferior, respectivamente, semelhante ao encontrado, quando a maior prevalência de uso de próteses foi no sexo feminino (86,46\%), já que é uma característica comum a vários estudos - o edentulismo é maior entre as mulheres $\mathrm{e}$, consequentemente, o percentual de uso de próteses dentárias também é maior (SILVA, 1999).

A presença de 21 ou mais dentes é um critério amplamente utilizado para considerar capacidade mastigatória satisfatória, sendo denomidada dentição funcional (SHEIHAM et al., 2002), entretanto, não foi possivel fazer essa classificação, visto que no questionário a pergunta sobre ausência dos dentes referese apenas à metade (16 dentes) ou mais. Há incentivo no Reino Unido, em relação à saúde dos idosos, para um maior cuidado às condições bucais, durante décadas, o que já pode ser verificado na proporção de adultos com 21 dentes ou mais que aumentou de $73 \%$, em 1978 , para $86 \%$, em 2009 , além do aumento no número de dentes em cerca de quatro dentes em média (21,9 para 25,7 dentes).

Outras grandes melhorias são esperadas, podendo estimar que mais de $90 \%$ dos adultos com 35 a 44 anos de idade, em 2009, tenham uma perspectiva realista de manter uma dentição funcional natural de 21 ou mais dentes por volta dos 80 anos (STELLE et al., 2012), o que seria bastante interessante que acontecesse no Brasil, visto que neste estudo, constatou maiores prevalências de perda $\geq 16$ dentes no grupo etário de 75 anos ou mais (89,31\%), em relação ao grupo de 60 a 74 anos (74,69\%), comprometendo ainda mais as condições bucais dos idosos mais velhos (SHEIMAN et al., 2002).

No Brasil, há uma triste crença de que a perda de dentes e o uso de prótese dentária são comuns à população idosa (CARDOSO e BUJES, 2010), como 
consequência natural do processo de envelhecimento, como única forma de tratamento disponivel quando jovens e/ou adultos (CALDAS JUNIOR et al.; 2005), e pode, portanto, exercer uma influência sobre a autopercepção das condições bucais e na qualidade de vida desta população, que neste estudo constatou-se $53,72 \%$ dos idosos com boas condições, sendo a prevalência dos homens maior $(57,26 \%)$ do que a das mulheres (51,36\%), o que não foi encontrado por Patussi et al. (2010), em que os idosos participantes do Projeto Saúde Bucal Brasil, em 2003, apresentaram piores condições bucais do que as idosas e, segundo a autopercepção, os idosos referiram condição bucal mais insatisfatória em comparação às idosas, provavelmente pela diferença no grupo etário avaliado (65 a 74 anos), mais novos em comparação ao deste estudo (PATTUSSI et al., 2010).

Apesar das más condições bucais, identificada pela perda de mais da metade dos dentes e, apesar do não uso de próteses dentárias, há uma predominância, de acordo com a autopercepção, de boas condições bucais (PIUVEZAM e LIMA, 2011), ou, é possível identificar por outra ótica, apesar de a maioria dos idosos avaliados afirmarem nunca ter limitações devido a problemas com dentes, gengivas ou próteses, o índice GOHAI foi 27,77 (considerando 36, como pontuação máxima, sob outro critério de pontuação), condizente com más condições bucais (HENRIQUES et al., 2007).

Em idosos, muitas vezes, as condições bucais não refletem o modo como percebem as reais condições de seus dentes, o uso ou a necessidade de próteses dentárias (MARTINS et al., 2010; COUSSON et al., 2012; HAIKAL et al., 2011), o que é evidenciado neste estudo, onde apesar de 77,53\% terem menos da metade dos dentes e $81,77 \%$ usarem próteses dentárias, a maioria $(53,72 \%)$ considerou sua condição bucal boa, segundo a autopercepção.

Cousson et al. (2012) avaliaram 97 idosos ( $\geq 60$ anos), franceses, classificados em controles (50 idosos sem uso ou necessidade de próteses) e casos (47 edêntulos totais sem prótese) e encontraram, $76 \%$, do grupo controle, com boas condições bucais, $20 \%$, regulares e $4 \%$ com más condições bucais, segundo o GOHAI, enquanto, nos casos, $26 \%$ com condições bucais boas, $23 \%$, regulares e $51 \%$, más condições bucais, evidenciando que o edentulismo total, quando não acompanhado de prótese, piora consideravelmente as condições bucais dos idosos, 
por isso Silva et al. (2011), estudando 876 idosos ( $\geq 65$ anos) de Campinas/SP, constataram que ter 20 dentes ou mais, usar prótese total nos dois arcos ou não necessitar delas, foram significantemente $(\mathrm{p}<0,05)$ associados com boas condições bucais, condição da maioria da amostra avaliada, mas que, quando associado à ausência de dentes e ao uso de prótese, as condições foram boas, evidenciando a incoerência na autopercepção da sua própria condição bucal por alguns idosos.

Esse resultado é equivalente ao encontrado no Projeto Saúde Bucal Brasil 2003 (BRASIL, 2004), quando 54\% dos idosos brasileiros consideraram suas condições bucais boas, segundo o GOHAI, constatando certa acomodação à situação precária ou, mesmo, de edentado (MARTINS et al., 2008).

Em recente estudo, com idosos do Estudo SABE, em 2006, cerca de metade $(44,7 \%)$ dos participantes teve uma pontuação GOHAI referente a boa condição bucal, semelhante ao encontrado neste estudo $(53,72 \%)$, enquanto $25,6 \%$ apresentou uma pontuação baixa, prevalência também equivalente ao deste estudo $(21,92 \%)$ (ANDRADE et al., 2012b).

Os participantes com 16 ou mais dentes perdidos eram mais propensos a ter uma melhoria nas condições bucais, segundo a autopercepção, sendo que melhoria e declínio nos escores funcionais GOHAI foram relacionados com o número de dentes perdidos (ANDRADE et al., 2012c).

Com o avanço das pesquisas com idosos, focando principalmente as condições bucais, autores (COUSSON et al., 2012; DE MARCHI et al., 2008; GILMONTOYA et al., 2008; RAUEN et al., 2006) concentram seus estudos na análise da associação entre risco para subnutrição e/ou subnutrição e condições bucais ruins ou pobres, apesar de existirem estudos brasileiros (BERNARDO et al., 2012; HILGERT et al., 2009) onde o excesso de peso também é influenciado por perda dentária parcial ou total não reabilitada com próteses, desde a idade adulta, associação que também pode ser verificada neste estudo, em idosos.

A alteração no estado nutricional foi identificada, principalmente quando se comparam as prevalências de baixo peso, em 2000 (16,22\%) e em 2006 (26,4\%), e de excesso de peso, em 2000 (37,23\%) e em 2006 (28,96\%), evidenciando uma redução do peso e, consequente, comprometimento do estado nutricional dos idosos, 
principalmente associado ao sexo e aos grupos etários, sem associação significativa do estado nutricional com condições bucais, em 2000 e em 2006.

Há uma lacuna importante na literatura de estudos de associação em que as condições bucais (perda dentária e o uso de prótese dentária, além das condições bucais percebidas pelos próprios idosos) são comparadas com alterações no estado nutricional de idosos não institucionalizados, em amostras representativas, de delineamento longitudinal.

Reddy et al. (2012) não encontraram associação entre condições bucais e estado nutricional, em idosos na India, mas este estava associado ao nível socioeconômico, característica não analisada neste estudo. A ausência de dentes, parcial e total, foi comparada ao estado nutricional e constatou-se não haver influência no IMC pelos níveis de edentulismo, semelhante a este estudo, que não apontou associação entre perda dentária e estado nutricional, identificado pela classificação da OPAS (2001) em relação aos valores de IMC.

Rauen et al. (2006) constataram, em 187 idosos institucionalizados de Florianópolis/SC, associação entre a dentição altamente comprometida - edêntulo sem prótese total superior ou inferior, e aqueles que apresentam 1 a 6 naturais ou mistas unidades funcionais, constituídos por dentes naturais e unidades prostéticos e subnutrição (IMC $<18,5 \mathrm{~kg} / \mathrm{m}^{2}$ ); e entre os que apresentaram dentição menos comprometida e excesso de peso, incluindo obesidade (IMC $\geq 30 \mathrm{~kg} / \mathrm{m}^{2}$ ), concluindo-se que a perda dentária e não uso de prótese poderiam comprometer o estado nutricional.

Nascimento et al. (2012), com 875 idosos domiciliados no município de Campinas/SP, constataram que idosos desdentados que não usavam próteses eram mais propensos a estarem com baixo peso $[\mathrm{OR}=3,94$; IC95\%: 1,14-13,64] e excesso de peso/obesidade [OR = 2,88; IC $95 \%: 1,12-7,40]$, corroborando que as condições bucais inadequadas estão associadas com o baixo peso e/ou excesso de peso, ou seja, associação direta com excesso de peso aqueles com condições bucais inadequadas, condição não verificada neste estudo, já que não foi analisado a condição de desdentados ou edêntulos totais. 
Mesas et al. (2010) estudaram 267 idosos (60 a 74 anos), de Londrina/PR, e verificaram maior risco para baixo peso entre más condições bucais, segundo autopercepção, independentemente do sexo, idade, classe econômica, educação, alimentação, depressão e uso de medicação, concluindo que a deterioração das condições bucais estava associada com déficit nutricional, relação não encontrada neste estudo, já que foi possível observar comprometimento do estado nutricional sem estar associado às condições bucais.

Hilgert et al. (2009) encontraram que idosos edêntulos com apenas uma prótese dentária (superior ou inferior) $(\mathrm{OR}=2,34$; IC95\%: 1,18-4,27) e aqueles com 1 a 8 dentes e nenhuma ou apenas prótese dentária parcial $(\mathrm{OR}=2,96$; IC95\%: 1,68-5,19) eram mais propensos a serem obesos, concluindo que condições bucais inadequadas, representada por ter menos dentes e não serem substituídos por próteses dentárias, foi associada com a obesidade, no sul do Brasil.

Gil-Montoya et al. (2008) avaliaram 2.860 idosos $(41,7 \%$ homens e $58,3 \%$ mulheres), com uma idade média de $73,7(6,8)$ anos, encontrando forte associação entre condições bucais regulares, segundo o GOHAI, com subnutrição em idosos, segundo a classificação da MAN, que, apesar do critério de avaliação do estado nutricional ser diferente, neste estudo houve uma associação indireta das condições bucais regulares com o excesso de peso $[R R=0,31[0,14-0,68])$, evidenciando a redução do peso e compromentimento do estado nutricional, em 2006, dentre aqueles com peso adequado, em 2000.

De Marchi et al. (2008) constataram que, dos 471 idosos, de Carlos Barbosa/RS, aqueles com condições bucais comprometidas apresentaram maior risco de subnutrição ( $O R=3,26$; IC95\%: 1,39-7,67) e a manutenção de alguns dentes teve um papel crucial no aumento da chance de a manutenção de um estado nutricional adequado, sendo que, nos casos em que se associou edentulismo com o uso de prótese dentária, obteve melhor estado nutricional, o que pode sugerir novas pesquisas, exame clínico bucal e análises estatísticas para se verificar se há associação, considerando edentulismo total com uso de prótese total com manutenção do estado nutricional adequado por esta população. 
Uma discussão interessante sobre alterações no estado nutricional de idosos pode ser feita, em relação às características distintas entre os sexos e grupos etários e tipos de estudos analisados.

Estudos longitudinais são necessários para determinar a magnitude das mudanças antropométricas com o envelhecimento, entretanto, o que se observa é a utilização de dados transversais usados frequentemente, mesmo não sendo apropriados para essa inferência (REA et al., 1997; SORKIN et al., 1999).

Nas distribuições de peso por grupo etário, Perissinotto et al. (2002), constataram em amostra transversal com 3.356 indivíduos italianos, deslocamento para valores inferiores de peso corpora, sendo que 14\% de idosos entre 65 e 69 anos passaram para o percentil 5 na avaliação do estado nutricional (considerando a distribuição em percentis dos valores de IMC comumente utilizados na prática clínica: $<20 \mathrm{~kg} / \mathrm{m}^{2}$ - baixo peso e $\geq 30 \mathrm{~kg} / \mathrm{m}^{2}$ - obesidade).

De fato, os impactos do envelhecimento sobre a composição corporal são contundentes em relação ao avançar da idade, pois é contabilizada diminuição da massa magra, com predomínio de massa gorda, sendo que o tecido adiposo não tem atividade metabólica significativa, diminuindo a taxa de metabolismo basal cerca de 2\% por década (TZANKOFF e NORRIS, 1978), entretanto, ao se analisar a tendência segundo sexo, a taxa de diminuição parece ser mais evidente para os homens do que para as mulheres, apresentando uma perda mais consistente da massa livre de gordura (GALLAGHER et al., 1997).

Segundo Elmadfa et al. (2003), 25\% de pessoas austríacas com idade de 65 a 74 anos foram consideradas com excesso de peso (IMC $>29 \mathrm{~kg} / \mathrm{m}^{2}$ ). No entanto, com o avançar da idade, do número de pessoas com excesso de peso diminui, totalizando apenas $11 \%$ entre os maiores de 84 anos. Ao mesmo tempo, a prevalência de baixo peso aumenta, atingindo $29 \%$ neste grupo etário, percentual próximo ao encontrado neste estudo, alterações no estado nutricional também encontrado por Perissinotto et al. (2002).

Kuczmarski et al. (2000) relacionaram a redução de peso com a idade, que nos homens essa redução representava $11 \%$ do peso de homens mais jovens ( 8 $\mathrm{kg}$ ), enquanto que nas mulheres a redução foi de cerca de $9 \%$ do peso das mulheres 
mais jovens $(6 \mathrm{~kg})$, corroborando que o aumento de baixo peso é mais evidente nos homens, com o avançar da idade.

É questionável, entretanto, se valores referentes à obesidade em idosos deveriam ser maiores, visto que o risco relativo de mortalidade associado ao IMC mais elevado diminui com a idade (STEVENS et al., 1998), sendo a desnutrição é preditor bem conhecido de mortalidade (VISSCHER et al., 2000), sendo a detecção precoce mais importante daqueles que podem estar em risco nutricional (PERISSINOTTO et al., 2002).

O delineamento longitudinal deste estudo sugere a possibilidade de identificação de relações causais entre as variáveis estudadas. Quanto ao estado nutricional, não foi constatada associação entre alterações do estado nutricional envolvendo indivíduos com baixo peso, em 2000, e as variáveis independentes. Entretanto, encontrou-se menor risco para excesso de peso em 2006, em idosos com condições bucais regulares e peso adequado em 2000; e maior chance para peso adequado em 2006, em homens com excesso de peso em 2000, evidenciando perda de peso com o avançar da idade, predispondo alteração e comprometendo o estado nutricional dessa população.

Em relação a este estudo, algumas limitações podem ser observadas:

Por se tratar de investigação da associação entre alterações do estado nutricional e condições bucais, em um país em desenvolvimento, a comparação direta destes resultados com a literatura é dificultada pelas diferenças nas características da população, já que a maioria dos estudos referidos foi conduzida em países desenvolvidos. As principais diferenças referem-se à idade para classificar uma pessoa como idosa: 60 anos, para indivíduos de países em desenvolvimento (BRASIL, 2003), e 65, para países desenvolvidos; e à falta de consenso para os valores de referência na classificação do estado nutricional de idosos, sendo utilizado neste estudo o sugerido pela OPAS (2001), a ser adotado no Estudo SABE, apesar da maior parte da literatura pesquisada e encontrada não adotar essa referência, dificultando assim a comparação com demais estudos. 
A dentição funcional, que considera a presença de 21 ou mais dentes, quantidade considerada suficiente para manter a mastigação satisfatória (SHEIHAM et al., 2002), é um critério muito utilizado, para avaliar as condições bucais. Entretanto, não foi avaliada neste estudo, porque os dados sobre o número de dentes estavam restritos às respostas do questionário, que eram categorizadas em metade ou mais dos dentes perdidos.

A análise da população estudada, em 2006, refere-se aos participantes, sobreviventes da pesquisa realizada em 2000, caracterizando, assim, seleção dos mais saudáveis, o que é esperado em estudos longitudinais, exigindo, portanto, bastante cautela na extrapolação dos resultados.

Este estudo sugere a necessidade da prevenção odontológica nesse grupo etário, evitando as más condições bucais em idosos, e os fatores que podem influenciar alterações no estado nutricional essa população, pelo crescimento da população idosa, em todo o mundo, e o possível aumento no impacto das condições bucais e do estado nutricional na qualidade de vida desses idosos. 
6. Conclusão 
Neste estudo, verificaram-se alterações no estado nutricional, referentes ao período de 2000 a 2006, evidenciadas por diminuição na proporção de idosos com excesso de peso (de 37 para 29\%) e aumento daqueles com baixo peso (de 16 para 26\%). Mudanças do estado nutricional, no período estudado, daqueles com baixo peso, em 2000, não foram associadas às condições bucais analisadas, enquanto os idosos com condições bucais regulares e que apresentavam peso adequado em 2000, tiveram menor risco para desenvolver excesso de peso em 2006. Em relação aos indivíduos com excesso de peso em 2000, os homens apresentaram maior chance para peso adequado em 2006, sem associação com as condições bucais. 


\section{REFERÊNCIAS}

ACUÑA, K.; CRUZ, T. Avaliação do estado nutricional de adultos e idosos e situação nutricional da população brasileira. Arquivos Brasileiros de Endocrinologia e Metabologia. vol. 48, n. 3, p. 345-61, 2004.

ALLISON, D. B. et al. Body mass index and all-cause mortality among people age 70 and over: the Longitudinal Study of Aging. International Journal of Obesity. vol. 21, p.424-31, 1997.

ANDRADE, F. B. et al. Factors related to poor self-perceived oral health among community-dwelling elderly individuals in São Paulo, Brazil. Cadernos de Saúde Pública. vol. 28, n. 10, p.1965-1975, 2012a.

ANDRADE, F. B. et al. Relationship between oral health-related quality of life, oral health, socioeconomic, and general health factors in elderly Brazilians. Journal of the American Geriatrics Society. vol. 60, p. 1755-1760, $2012 \mathrm{~b}$.

ANDRADE, F. B. et al. Correlates of change in self-perceived oral health among older adults in Brazil. The Journal of the American Dental Association. vol. 143, n. 5 , p. $488-495,2012$ c.

ATCHISON, K. A. The Geriatric Oral Health Assessment Index. In: SLADE, G. D. (Org.). Measuring oral health and quality of life. Chapel Hill: University of North Carolina, Dental Ecology. cap. 7, p. 71-80, 1997.

ATCHISON, K. A.; DOLAN, T. A. Development of geriatric oral health assessment index. Journal of Dental Education. vol. 54, n. 11, p. 680-7, 1990.

ATCHISON, K. A.; GIFT, H. C. Perceived oral health in a diverse sample. Advances in Dental Research. vol. 11, p. 272-80, 1997.

BARBOSA, A. R. et al. Anthropometry of elderly residents in the city of São Paulo, Brazil. Cadernos de Saúde Publica, vol. 21, n. 6, p. 1929-38, 2005.

BARBATO, P. R. et al. Perdas dentárias e fatores sociais, demográficos e de serviços associados em adultos brasileiros: uma análise dos dados dos estudos epidemiológicos nacionais (Projeto SB Brasil 2002-2003). Cadernos de Saúde Pública. vol. 23, n. 8, p. 1803-14, 2007.

BARRETO, S. M.; PASSOS, V. M. A.; LIMA-COSTA, M. F. F. Obesity and underweight among Brazilian elderly. The Bambuí Health and Aging Study. Cadernos de Saúde Pública. vol. 19, n. 2, p. 605-12, 2003. 
BAUER, J. M. et al. Comparison of the Mini Nutritional Assessment, Subjective Global Assessment, and Nutritional Risk Screening (NRS 2002) for nutritional screening and assessment in geriatric hospital patients. Archives of Gerontology and Geriatrics. vol. 38, n. 5, p. 322-7, 2005.

BENEDETTI, T. R. B.; FERREIRA DE MELO, A. L. S.; GONÇALVES, L. H. T. Idosos de Florianópolis: autopercepção das condições de saúde bucal e utilização de serviços odontológicos. Ciência e Saúde Coletiva, vol. 12, n. 6, p.1683-90, 2007.

BERNARDO, C. O. et al. Association between tooth loss and obesity in Brazilian adults: a population-based study. Revista de Saúde Pública. vol. 46, n. 5, p. 834-42, 2012.

BRASIL. Ministério da Saúde. Relatório Final da $1^{\text {a }}$ Conferência Nacional de Saúde Bucal. Brasília (DF): Ministério da Saúde, 1986.

BRASIL. Ministério da Saúde. Estatuto do Idoso. Brasília: Editora MS; 2003.

BRASIL. Coordenação Nacional de Saúde Bucal, Departamento de Atenção Básica, Secretaria de Atenção à Saúde, Ministério da Saúde. Projeto SB BRASIL 2003: condições de saúde bucal da população brasileira 2002-2003. Resultados principais. Brasília: Ministério da Saúde; 2004.

BRASIL. Ministério da Saúde. Secretaria de Atenção à Saúde. Departamento de Ações Programáticas e Estratégicas - Área Técnica Saúde do Idoso. Atenção à saúde da pessoa idosa e envelhecimento. - Brasília , 2010. 44 p. - (Série B. Textos Básicos de Saúde) (Série Pactos pela Saúde 2006, v. 12).

BRASIL. Ministério da Saúde - Secretaria de Atenção à Saúde/Secretaria de Vigilância em Saúde - Departamento de Atenção Básica - Coordenação Geral de Saúde Bucal. Projeto SB Brasil 2010: Pesquisa Nacional de Saúde Bucal Resultados Principais. Brasília/DF; 2011. 92p.

BUENO, J. M. et al. Avaliação nutricional e prevalência de doenças crônicas não transmissíveis em idosos pertencentes a um programa assistencial. Ciência e Saúde Coletiva. vol. 13, n. 4, p. 1237-46, 2008.

BURR, M. L., PHILlIPS, K. M. Anthropometric norms in the elderly. British Journal of Nutrition. vol. 5, n. 2, p. 165-9, mar., 1984. 
CABRERA, M. A. S.; ANDRADE, S. M. WAJNGARTEN, M. Causas de mortalidade em idosos: estudo de seguimento de nove anos. Geriatria \& Gerontologia. vol. 1, n. 1, p. 14-20, 2007.

CABRERA, M. A. S.; JACOB FILHO, W. J. Obesidade em idosos: prevalência, distribuição e associação com hábitos e co-morbidades. Arquivos Brasileiros de Endocrinologia e Metabologia. vol. 45, n. 5, p. 494-501, 2001.

CALDAS JÚNIOR, A. F. et al. O impacto do edentulismo na qualidade de vida de idosos. Revista de Ciências Médicas. Campinas, v. 14, n. 3, p. 229-38, 2005.

CAMARANO, A. A.; PASINATO, M. T. O envelhecimento populacional na agenda das políticas públicas. In: CAMARANO, A. A. Os novos idosos brasileiros muito além dos 60?, Rio de Janeiro, IPEA, 2004.

CAMARANO, A. A.; PASINATO, M. T. Introdução. In: CAMARANO, A. A. Os Novos Idosos Brasileiros: Muito Além dos 60? - Rio de Janeiro: IPEA, 2004a.

CAMARANO, A. A. Envelhecimento da população brasileira: uma contribuição demográfica. Rio de Janeiro: IPEA, 2002 (Texto para Discussão, 858).

CARDOSO, E. M. et al. Condição de saúde bucal em idosos residentes no município de Manaus, Amazonas: estimativas por sexo. Revista Brasileira de Epidemiologia, vol. 14, n. 1, p. 131-40, 2011.

CARDOSO, M. C. A. F.; BUJES, R. V. A saúde bucal e as funções da mastigação e deglutição nos idosos. Estudos interdisciplinares sobre o envelhecimento. Porto Alegre, v. 15, n. 1, p. 53-67, 2010.

CERVI, A., FRANCESCHINI, S. C. C., PRIORE, S. E. Análise crítica do uso do índice de massa corporal para idosos. Revista de Nutrição. vol. 18, n. 6, p. 765-75, 2005.

COBAN, E.; TIMURAGAOGLU, A.; MERIÇ, M. Iron deficiency anemia and the elderly: prevalence and endoscopic evaluation of the gastrointertinal tract in outpatients. Acta Haematologica. vol. 110, n. 1, p. 25-8, 2003.

COLUSSI, C. F., FREITAS, S. F. T. Aspectos epidemiológicos da saúde bucal do idoso no Brasil. Cadernos de Saúde Pública, vol. 18, p 1313-20, 2002.

COSTA, M. F. F. L. et al. Projeto Bambuí: um Estudo Epidemiológico de Características Sociodemográficas, Suporte Social e Indicadores de Condição de 
Saúde dos Idosos em Comparação aos Adultos Jovens. Informe Epidemiológico do SUS. vol. 11, n. 2, p. 91-105, 2002.

COUSSON, P. Y. et al. Nutritional status, dietary intake and oral quality of life in elderly complete denture wearers. Gerodontology. vol. 29, n. 2, p. 685-92, 2012.

DELACORTE, R. R. et al. Mini-nutritional assessment score and the risk for undernutrition in free-living older persons. The Journal of Nutrition Health and Aging. vol. 8, n. 6, p. 531-4, 2004.

DE MARCHI, R. J. et al. Association between oral health status and nutritional status in south Brazilian independent-living older people. Nutrition. vol. 24, p. 546$553,2008$.

DIAS-DA-COSTA, J. S.; et al. Prevalência de capacidade mastigatória insatisfatória e fatores associados em idosos brasileiros. Cadernos de Saúde Pública. vol. 26, n. 1, p. 79-88, 2010.

ELMADFA, I.; et al. Österreichischer Ernährungsbericht, 1, Aufl., Wien, 2003.

ELMADFA, I.; MEYER, A. L. Body composition, changing physiological functions and nutrient requirements of the elderly. Annals of Nutrition and Metabolism. vol.52, suppl 1, p. 2-5, 2008.

EMED, T. C. X., KRONBAUER, A., MAGNONI, D. Mini-avaliação nutricional como indicador de diagnóstico em idosos de asilos. Revista Brasileira de Nutrição Clínica. vol. 21, n. 3, p.219-23, 2006.

FINCH, S. et al. National Diet and Nutrition Survey: people aged 65 years and over. Report of the diet and nutrition survey. London: The Stationery Office, vol 1.1998.

FLORENTINO, A. M. Influências dos fatores econômicos, sociais e psicológicos no estado nutricional de idosos. In: FRANK, A. A.; SOARES, E. A. Nutrição no Envelhecer. São Paulo. Atheneu, 2002. p. 3-11.

GALLAGHER, D. et al. Appendicular skeletal muscle mass: effects of age, gender, and ethnicity. Journal of Applied Physiology. vol. 83, p. 229-239, 1997.

GAIÃO, L. R.; ALMEIDA, M. E. L.; HEUKELBACH, J. Perfil epidemiológico da cárie dentária, doença periodontal, uso e necessidade de prótese em idosos residentes 
em uma instituição na cidade de Fortaleza, Ceará. Revista Brasileira de Epidemiologia, vol. 8, n. 3, p. 316-23, 2005.

GARCIA, A. N. M.; ROMANI, S. A. M; LIRA, P. I. C. Indicadores antropométricos na avaliação nutricional de idosos: um estudo comparativo. Revista de Nutrição. vol. 20 , n. 4 , p. $371-78,2007$.

GILBERT L. Social factors and self-assessed oral health in South Africa. Community Dentistry and Oral Epidemiology, vol. 22, n. 1, p. 47-51, 1994.

GIL-MONTOYA, J. A. et al. Oral Health-Related Quality of Life and Nutritional Status. Journal of Public Health Dentistry. vol. 68, n. 2, p. 88-93, 2008.

HAIKAL, D. S. et al. Autopercepção da saúde bucal e impacto na qualidade de vida do idoso: uma abordagem quanti-qualitativa. Ciência \& Saúde Coletiva, vol. 16, n. 7,p. 3317-29, 2011.

HASSEL, A. J. et al. German Version of the GOHAI. Community Dentistry and Oral Epidemiology, vol. 36, p. 34-42, 2008.

HEIAT, A.; VACCARINO, V.; KRUMHOLS, H. M., An evidence-based assessment of Federal Guidelines for overweight and obesity as they apply to elderly persons. Archives of Internal Medicine. vol. 161, p. 1194-203. 2001.

HENRIQUES, C. et al. Autopercepção das condições de saúde bucal de idosos do município de Araraquara-SP. Ciência Odontológica Brasileira, vol. 10, n. 3, p. 6773, 2007.

HICKSON, M.Malnutrition and ageing. Postgrad Medical Journal. vol. 82, n. 963, p. 2-8, 2006.

HILGERT, J. B. et al. Oral status and its association with obesity in southern Brazilian older people. Gerodontology. vol. 26, p. 46-52, 2009.

HOUSTON, D. K.; NICKLAS, B. J.; ZIZZA, C. A. Weighty concerns: the growing prevalence of obesity among older adults. Journal of the American Dietetic Association. vol. 109, n, 11, p.1886-95, 2009.

IBGE - Instituto Brasileiro de Geografia e Estatística. Pesquisa de orçamentos familiares 2002-2003: primeiros resultados: Brasil e grandes regiões. Rio de Janeiro: Instituto Brasileiro de Geografia e Estatística; 2004. 
IBGE - Instituto Brasileiro de Geografia e Estatística. Diretoria de Pesquisas Coordenação de População e Indicadores Sociais. Estudos e Pesquisas Informação Demográfica e Socioeconômica. Número 24. Projeção da população do Brasil por sexo e idade 1980-2050 - Revisão 2008 - Rio de Janeiro, 2008. 93p.

IBGE - Instituto Brasileiro de Geografia e Estatística. Censo Demográfico 2010. Internet: www.ibge.gov.br. Acesso em 20/01/2013.

INELMEN, E. M. et al. Dietary intake and nutritional status in Italian elderly subjects. Journal of Nutrition, Health \& Aging. vol. 4, p. 91-101, 2000.

KRESSIN, N. R. The oral health-related quality of life measure (OHQOL). In: SLADE, G.D. Measuring oral health and quality of life. University of North Carolina, School of Dentistry, pp. 113-20, 1997.

LEÃO, A. T. T.; SHEIHAM, A. The development of a sociodental measure of dental impacts on daily living. Community Dental Health. vol. 13, n, 1, p.22-6, 1996.

LEBRÃO, M. L.; DUARTE, Y. A. O. Desafios de um estudo longitudinal: O projeto SABE. Saúde Coletiva, vol. 5, p. 166-7, 2008.

LEBRÃO, M. L.; LAURENTI, R. Saúde, Bem-Estar e Envelhecimento: o estudo SABE no Município de São Paulo. Revista Brasileira de Epidemiologia, vol. 8, $\mathrm{n}$. 2, p. 127-41, 2005.

LEITE-CAVALCANTI, C. et al. Prevalência de doenças crônicas e estado nutricional em um grupo de idosos brasileiros. Revista de Saúde Pública. vol. 11, n. 6, p. 865-877, 2009.

LOCKER, D. Applications of self-reported assessments of oral health outcomes. Journal of Dental Education, vol. 60, p. 494-500, 1996.

LOEF, M.; WALACH, H. The combined effects of healthy lifestyle behaviors on all cause mortality: a systematic review and meta-analysis. American Journal of Preventive Medicine. vol. 55, n. 3, p. 163-70, 2012.

LUKASKI, $\mathrm{H}$. Methods for the assessment of human body composition: traditional and new. The American Journal of Clinical Nutrition, vol. 46, p. 537-56, 1987.

KUCZMARSKI, M. F.; KUCKZMARSKI, R.; NAJJAR, M. Descriptive anthropometric reference data for older Americans. Journal of The American Dietetic Association. vol. 100, p. 59-66, 2000. 
MCWHIRTER, J. P.; PENNINGTON, C. R. Incidence and recognition of malnutrition in hospital. Archives of British Medical Journal, vol. 308, p. 945-8, 1994.

MARCENES, W. et al. The relationship between dental status, food selection, nutrient intake, nutritional status, and body mass index in older people. Cadernos de Saúde Pública. vol. 19, n. 3, p. 809-16, 2003.

MARTINS, A. M. E. B. L., BARRETO, S. M., PORDEUS, I. A. Factors associated to self perceived need of dental care among Brazilian elderly. Revista de Saúde Pública, vol. 42, n. 3, p. 487-96, 2008.

MARTINS, E. O. B. et al. Análise da condição bucal de pacientes idosos atendidos na clínica odontológica da Universidade Tiradentes de Aracaju / SE. Revista de Odontologia Clínico-Científica, vol. 9, n. 2, p. 171-5, 2010.

MARUCCI, M. F. N. Fatores nutricionais determinantes da saúde. In: JACOB FILHO, W. Promoção da Saúde do Idoso. São Paulo: Lemos. 1998. p. 93

MATSUDO, S. M., MATSUDO, V. K. R., BARROS NETO, T. L. Impacto do envelhecimento nas variáveis antropométricas neuromotoras e metabólicas da aptidão física. Revista Brasileira de Ciência e Movimento. vol. 8, n. 4, p. 21-32, 2000.

MESAS, A. E. et al. Salud oral y déficit nutricional en adultos mayores no institucionalizados en Londrina, Paraná, Brasil. Revista Brasileira de Epidemiologia, vol. 13, n. 3, p. 434-45, 2010.

MOREIRA, R. S.; NICO, L. S.; SOUSA, M. L. R. Fatores associados à necessidade subjetiva de tratamento odontológico em idosos brasileiros. Cadernos de Saúde Pública. vol. 25, n. 12, p. 2661-71, 2009.

MOREIRA, R. S. et al. A saúde bucal do idoso brasileiro: revisão sistemática sobre o quadro epidemiológico e acesso aos serviços de saúde bucal. Cadernos de Saúde Pública, vol. 21, n. 6, p. 1665-75, 2005.

MURASCO, D. M.; BERNSTEIN, E. D., Nutrition and Aging. In: HAZZARD, W. R. (ed.) et al. Principles of Geriatric Medicine and Gerontology, pp. 81-116, 4th Ed., New York: McGraw-Hill. 1998.

NARVAI, P. C.; ANTUNES, J. L. F. Saúde bucal: a autopercepção da mutilação e das incapacidades. In: LEBRÃO, M. L.; DUARTE, Y. A. O. SABE - Saúde, Bem- 
estar e Envelhecimento - O Projeto Sabe no município de São Paulo: uma abordagem inicial. Brasília: Organização Pan-Americana da Saúde, p. 119-40, 2003.

NASCIMENTO, T. L. et al. Association between underweight and overweight/obesity with oral health among independently living Brazilian elderly. Nutrition. vol. 29, n. 1, p.152-7, 2013.

NSI - Nutrition screening initiative incorporating nutrition screening and interventions into medical practice: A monograph for physicians. Washington, DC:Nutrition Screening Initiative, 1994.

OMERAN, M. L, MORLEY, J. E. Assessment of Protein Energy Malnutrition in Older Person. Part I: History, Examonation, Body Composition and Screening Tools. Nutrition. vol. 16, p. 50-63, 2000.

OMS - Organização Mundial da Saúde. Manejo da desnutrição grave: um manual para profissionais de saúde de nível superior e suas equipes auxiliares. Genebra, 2000.

OPAS - ORGANIZACIÓN PANAMERICANA DE LA SALUD. División de Promoción y Protección de la Salud (HPP). XXXVI Reunión del Comitê Asesor de Investigaciones en Salud - Encuestra Multicêntrica - Salud Bienestar y Envejecimiento (SABE) en America Latina y el Caribe - Informe preliminar. Washington, D.C. Mayo de 2001.

OTERO, U. B. et al. Mortalidade por desnutrição em idosos, região Sudeste do Brasil, 1980-1997. Revista de Saúde Pública, vol. 36, n. 2, p.141-8, 2002.

PAPALÉO NETO, M.; BORGONOVI, N. Biologia e teorias do envelhecimento. In: PAPALÉO NETO, M; BORGONOVI, N. Gerontologia: a velhice e o envelhecimento em visão globalizada. São Paulo: Atheneu; 2002. p. 284-96.

PATTUSSI, M. P. et al. Self-rated oral health and associated factors in Brazilian elders. Community Dentistry and Oral Epidemiology, vol. 38, n. 4, p. 348-59, 2010 .

PELÁEZ, M.; et al. Survey on Aging, Health and Wellbeing, 2000. Geneva: Pan American Health Organization (PAHO/WHO); 2003.

PERISSINOTTO, E. et al. Anthropometric measurements in the elderly: age and gender differences. British Journal of Nutrition. vol. 87, p. 177-86, 2002. 
PETERSEN, P. E. Global research challenges for oral health. Global Forum Update on Research for Health. v. 2, p. 181-4, 2003.

PINTO, M. L. Situação odontológica do idoso no Brasil. Revista da Faculdade de Odontologia da UFBA. vol. 7, p. 23-8, 1987.

PINTO, V. G. Identificação de problemas. In: PINTO, V. G. Saúde bucal coletiva, São Paulo: Santos; p.139-222, 2000.

PIUVEZAM, G,; LIMA, K. C. Self-perceived oral health status in institutionalized elderly in Brazil. Archives of Gerontology and Geriatrics. vol. 55, p.5-11, 2012.

PUCCA Jr, G. A. Saúde bucal do idoso: aspectos sociais e preventivos. In: PAPALÉO NETTO, M., org. Gerontologia. São Paulo, Atheneu, 1999. p. 297-310.

PUCCA Jr, G. A. Perfil do edentulismo e do uso de prótese dentária em idosos residentes no município de São Paulo. [dissertação] São Paulo: Escola Paulista de Medicina, Universidade Federal de São Paulo; 1998.

RAMOS, L. R., 2002. Epidemiologia do envelhecimento. In: FREITAS, E. V. et al. Tratado de Geriatria e Gerontologia. Guanabara Koogan, Rio de Janeiro, Cap. 7, p. $72-78$.

RAMOS, L. R. Um país que envelhece. In: SPDM - Associação Paulista para o Desenvolvimento da Medicina e Interfarma - Associação da Indústria Farmacêutica de Pesquisa. $1^{\text {a }}$ ed. São Paulo: Cultura Acadêmica Editora, 2012. p. $33-41$.

RAO, J. N. K.; SCOTT, A. J. On Chi-Squared Tests for Multiway Contingency Tables with Cell Proportions Estimated from Survey Data. The Annals of Statistics. vol.12, n. 1, p.46-60, 1984.

RAUEN, M. S. et al. Oral Condition and Its Relationship to Nutritional Status in the Institutionalized Elderly Population. Journal of the American Dietetic Association. vol. 106, p. 1112-14, 2006.

REDDY, N. S. et al. Epidemiological Survey on Edentulousness. The Journal of Contemporary Dental Practice. vol. 13, n. 4, p. 562-70, 2012.

REIS, S. C. G. B. et al. Condição de saúde bucal de idosos institucionalizados em Goiânia-GO. Revista Brasileira de Epidemiologia, vol. 8, n. 1, p. 67-73, 2005. 
ROSA, A. G. F. et al. Condições de saúde bucal em pessoas de 60 anos ou mais no Município de São Paulo (Brasil). Revista de Saúde Pública, vol. 26, p. 155-60, 1992.

ROUBENOFF, R. The pathophysiology of wasting in the elderly. Journal of Nutrition. vol. 129, p. 256S-9S, 1999.

SÁNCHEZ-GARCÍA, S. et al. Anthropometric measures and nutritional status in a healthy elderly population. BMC Public Health. vol. 7, n. 2, p 1-9, 2007.

SLADE, G. D.; SPENCER, A. J. Development and evaluation of the Oral Health Impact Profile. Community Dental Health. vol. 11, n. 1, p.3-11, 1994.

SLADE, G. D. Derivation and validation of a short-form oral health impact profile. Community Dental Epidemiology, v.25, n.4, p.284-90, 1997.

SANTOS, D. M.; SICHIERI, R. Índice de massa corporal e indicadores antropométricos de adiposidade em idosos. Revista de Saúde Pública, vol. 39, n. 2, p. $163-8,2005$.

SÃO PAULO (SP). Secretaria Municipal de Saúde. Coordenação de Epidemiologia e Informação - CEInfo. Boletim ISA - Capital 2008, n 2, 2011: Estado nutricional, insatisfação em relação ao peso atual e comportamento relacionado ao desejo de emagrecer na cidade de São Paulo. 2a edição. São Paulo: CEInfo, 2010.

SAVOCA, M. R. et al. Severe tooth loss in older adults as a key indicator of compromised dietary quality. Public Health Nutrition, vol. 13, n. 4, p. 466-74, 2009.

SHEIHAM, A. et al. The relationship between oral health status and body mass index among older people: a national survey of older people in Great Britain. British Dental Journal. vol. 192, p. 703-6, 2002.

SHINKAI, R. S. A.; CURY, A. A. D. B O papel da odontologia na equipe interdisciplinar: contribuindo para a atenção integral ao idoso. Cadernos de Saúde Pública. vol.16, no.4, p.1099-109, 2000.

SILVA, R.; RAUEN, M. S.; MOREIRA, E. A. M. Hábitos alimentares em idosos. Revista Brasileira de Nutrição Clínica. vol. 20, n. 4, p. 246-50, 2005.

SILVA, N, N. Aspectos metodológicos - Processo de amostragem. In: LEBRÃO, M. L.; DUARTE, Y. A. O. SABE - Saúde, Bem-estar e Envelhecimento - O Projeto 
SABE no município de São Paulo: uma abordagem inicial. Brasília: Organização Pan-Americana de Saúde, 2003. p. 47-58.

SILVA, S. R. C.; CASTELHANOS FERNANDES, R. A. Autopercepção das condições de saúde bucal por idosos. Revista de Saúde Pública, vol. 35, n. 4, p. 349-55, 2001.

SILVA, D. D. et al. Autopercepção da saúde bucal em idosos e fatores associados em Campinas, SP, 2008-2009. Revista de Saúde Pública 2011, ahead of print Epub Sep 16, 2011.

SILVA, E. F. A.; SOUSA, M. L. R. Autopercepção da saúde bucal e satisfação com a vida em mulheres idosas usuárias de prótese total. Revista de Odontologia da Universidade de São Paulo, vol. 18, n. 1, p. 61-5, jan./abr.; 2006.

SILVA, D. D.; SOUZA, M. L. R.; WADA, R. S. Saúde bucal em adultos e idosos na cidade de Rio Claro. São Paulo, Brasil. Cadernos de Saúde Pública, Rio de Janeiro, v. 20 , n. 2 , p. $626-31,2004$.

SILVA, S. R. C.; VALSECKI JR., A. Avaliação das condições de saúde bucal dos idosos em um município brasileiro. Revista Panamericana de Salud Publica, Washington, v. 8, n. 4, p. 268-71, 2000.

SILVEIRA, E. A.; KAC, G.; BARBOSA, L. S. Prevalência e fatores associados à obesidade em idosos residentes em Pelotas, Rio Grande do Sul, Brasil: classificação da obesidade segundo dois pontos de corte do índice de massa corporal. Cadernos de Saúde Pública. vol. 25, n. 7, p. 1569-77, jul, 2009.

SOUZA, E. H. A. et al. Impacto da saúde bucal no cotidiano de idosos institucionalizados e não institucionalizados da cidade do Recife (PE, Brasil). Ciência \& Saúde Coletiva, vol.15, n. 6, p. 2955-64, 2010.

STEELE, J. G. et al. J. Adult Dental Health Survey 2009: transformations in British oral health 1968-2009. British Dental Journal. vol. 213, n. 10, 2012.

STEVENS, J. et al. The effect of age on the association between body-mass index and mortality. New England Journal of Medicine. vol. 338, p. 1-7, 1998.

TAVARES, E. L.; ANJOS, L. A. Perfil antropométrico da população idosa brasileira. Resultados da Pesquisa Nacional sobre Saúde e Nutrição. Cadernos de Saúde Pública, Rio de Janeiro, vol. 15, n. 4, p. 759-68, out./dez., 1999. 
TEIXEIRA, D. S. C. Condições de saúde bucal dos idosos moradores no município de São Paulo. 2007. Dissertação (Mestrado em Serviços de Saúde Pública) - Faculdade de Saúde Pública, Universidade de São Paulo, São Paulo, 2007. Disponivel em: <http://www.teses.usp.br/teses/disponiveis/6/6135/tde-17032008140604/>. Acesso em: 2012-02-29.

THOMAS, D. R. et al. Nutritional management in long-term care: Development of a clinical guideline. Journal of Gerontolology: Medical Sciences. vol. 55A, p.M725M34 2000.

TZANKOFF, S. P.; NORRIS, A. H. Longitudinal changes in basal metabolism in man. Journal of Applied Physiology. vol. 45, p. 536-539, 1978.

UNITED NATIONS. Department of Economic and Social Affairs, Population Division. Population Ageing 2006. New York, 2006. Disponível no site: http://www.un.org/esa/population/publications/ageing/ageing2006.htm. Acesso em 7 de abril de 2013.

VISSCHER, T. L. S. et al. Underweight and overweight in relation to mortality among men aged 40-59 and 50-69 years. American Journal of Epidemiology. vol. 151 , p. 660-666, 2000.

WHO - World Health Organization. Physical Status: The Use and Interpretation of Anthropometry. Geneva: 1995 (Technical Report Series 854)

WHO - World Health Organization. Obesity: Preventing and managing the global epidemic. Report of a WHO consultation on obesity. Geneva, 1998. (Technical Report Series, 894).

WHO - World Health Organization. Active Ageing - A Policy Framework. Geneva: World Health Organization, 2002.

WHO - World Health Organization. Joint reported of expert consultation. Diet, nutrition and the prevention of chronic diseases. Geneva, 2003. (WHO Technical Report Series, 916). 
Anexos 
ANEXO I. Aprovação pelo Comitê de Ética em Pesquisa (COEP) em 1999.

\section{UNIVERSIDADE DE SÃO PAULO \\ FACULDADE DE SAÚDE PÚBLICA \\ COMTTE DE ETICA EM PESQUISA DA FSP/USP - COEP \\ Av. Dr. Amaldo, 715 - CEP 01246-904 - São Paulo - Brasil \\ Telefones: (55-11) $30667742-\operatorname{fax}(55-11) 30647314$}

Or.COEP/67/99

24 de maio de 1999

Pelo presente, informo que o Comitê de Ėtica em Pesquisa, aprovou, em sua 3."199, Sessão Ordinária, de 19.05.99, de acordo com os requisitos da Resoluçāo CNS/196/96, o Projeto de Pesquisa "AS CONDIÇÕES DE SAÚdE DOS IDOSOS NA AMÉRIC.A DO SUL E CARIBE”, apresentado pelo pesquisador Ruy Laurenti, devendo ser remetido à CONEP conforme as normas da Resolução 196/96.

Atenciosamente,

Prof.Dr. Paulo An ondig de Carvalho Fortes

Vice-Coordenador do Comite fe hyifa em Pesquisa da FSP-COEP 
ANEXO II. Aprovação pela Comissão Nacional de Ética em Pesquisa (CONEP) em 1999.

\section{MINISTERIO DA SAUDE}

Conselno Nacional de Saude

Comissto Necmal de Elica em Pesquisa - CONEP

$$
\text { P }
$$

\section{PARECER N 31ERO}

Proceseo $n \cdot 25000.024350 / 00-00$

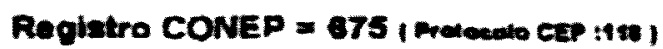

Proleto de Pesqulsa: AAs condifoes de sulde dos rosos ne Amorice do Sul Canton:.

Pesculeador Responsival: Dr Ruy Laurenti

Inethulello: F aculdede de Saude Püblica / USP

Aree Tematica Especial Pesquisa com cooperecto estrangare

Ao se proceder à analise do protocolo em questfo. cabem as sepuintes consideraç6es:

a) as informaçbes enwades utendem aos aspectos fundementais das Res CNS 196/98 251/97. sobre Dirotrizes Nomas Regulamentadoras de Pesquitere Envolvendo Seres Humanos:

b) o projeto foi aprovado pelo Comite de Ética em Pesquise - CEP da instiaute to

Diente do exposto, - Comissho Naolonal de Etica em Pesquiea CONEP, de acordo com a atribuicbes da Res. CNS 10aros, manifeata - se pela aprovacto do projeto de pesquisa proposto, com a seouinte recomendaglo : ever acompanhada pelo CEP:

1) Crçamento financeiro detolnado. especticanoo a remuneraclo do pesquisedor (Res CNS 196\%. VI:"')

Sltwacto : Projeto aprovado cam recomendagto.

Brastha. 17 de junto ce 1999.

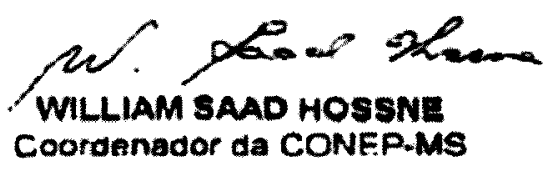


ANEXO III. Aprovação pelo Comitê de Ética em Pesquisa (COEP) em 2006.

\section{Universidade de Säo Paulo}

Faculdade de Saúde Pública

\section{COMITÊ DE ÉTICA. COEP}

Av. Dr. Arnalun, 715 - Asseisuria Acadènica-CEP 01246-904 - Să Paulo-Brasil Telefones: (55-11) 3066-7779- c-mail: cexpentspenphr

\section{Of.COEP/83/06}

Pelo presente, informo que o Comitê de Ética em Pesquisa da Faculdade de Saúde Pública da Universidade de São Paulo.COEP, aprovou o Prolocolo de Pesquisa n. ${ }^{\circ}$ 1345, intitulado: "PROJETO SABE-2005 - SAÚDE, BEM-ESTAR E ENVELHECIMENTO. AS CONDIÇÕES DE SAÚdE E DE VIDA DOS IDOSOS NO MUNICIPIO DE SÄO PAULO", apresentado pela pesquisadora Maria Lúcia Lebrão.

Atenciosamente,

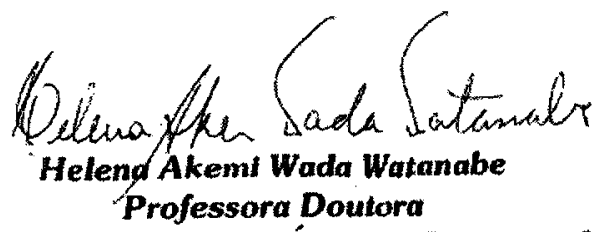

Vice-Coordenadora do Comitê de F́tica em Pesquisa da FSP-COEP 
ANEXO IV. Parecer consubstanciado do Comitê de Ética em Pesquisa (CEP) da Faculdade de Saúde Pública da Universidade de São Paulo (FSP/USP), em 2012.

Pesquisador: Juliana Magalhães da Cunha Rêgo

Título: Associação do estado nutricional com ausência referida de dentes ou de prótese e autopercepção das condições bucais de idosos domiciliados no município de São Paulo - Estudo SABE: Saúde, Bem-Estar e Envelhecimento, 2000 e 2006.

Instituição: Faculdade de Saúde Pública da Universidade de São Paulo - FSP/USP

Versão: 1

CAAE: 01357812.0 .0000 .5421

\section{PARECER CONSUBSTANCIADO DO CEP}

Número do Parecer: 48324

Data da Relatoria: $22 / 06 / 2012$

\section{PROJETO DE PESQUISA}

\section{Área Temática:}

Projeto de pesquisa bem elaborado, utilizando dados de um estudo maior (As condições de saúde do idoso da America Latina e Caribe - Parecer CONEP - 315/99) Pretende estudar a relação da saúde bucal e o estado nutricional.

\section{Apresentação do Projeto:}

Verificar a associação do estado nutricional com ausência de dentes ou de próteses e autopercepção das condições bucais de uma coorte de idosos, domiciliados no município de São Paulo, segundo sexo e grupos etários, em 2000 e 2006.

\section{Objetivo da Pesquisa:}

Estudará dados secundários, já coletados em anos anteriores da pesquisa - As condições de saúde do idoso da America Latina e Caribe - Parecer CONEP - 315/99. Os benefícios serão importantes. 
Avaliação dos Riscos e Benefícios:

Estudara dados secundários, já coletados em anos anteriores da pesquisa - As condições de saúde do idoso da America Latina e Caribe - Parecer CONEP - 315/99. Os benefícios serão importantes.

Como toda pesquisa utilizando e analisando dados desse estudo fonte são importantes para saúde dessa faixa etária.

Comentários e Considerações sobre a Pesquisa:

Não se aplica

Considerações sobre os Termos de apresentação obrigatória:

Sem recomendações

Recomendações:

Bom projeto.

Conclusões ou Pendências e Lista de Inadequações:

Aprovado

Situação do Parecer:

Não

Necessita Apreciação da CONEP:

Não

02 de Julho de 2012

Assinado por:

Claudio Leone 
ANEXO V. Autorização para utilização dos dados pela responsável pelo Estudo SABE, no Brasil.

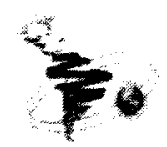

ESTUDO SABE:

SAÚDE, BEM-ESTAR E ENVELHECIMENTO

$S$ A B E

Estudo longitudinal sobre as condiçōes de vida e de saúde dos idosos do Município de São Paulo

\section{DECLARAÇÃo}

Declaro que tenho conhecimento e aprovo o uso dos dados do Estudo SABE pela aluna Juliana Magalhães da Cunha Rêgo, orientanda da Profa. Dra Maria de Fátima Nunes Marucci. Declaro, ainda, que o projeto da aluna faz parte dos objetivos do projeto original.

São Paulo, 12 de março de 2012

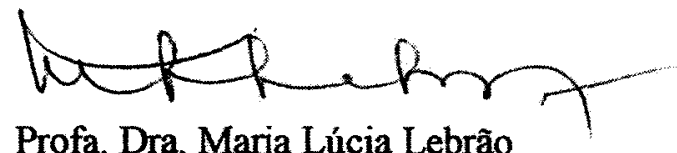

Coordenadora 


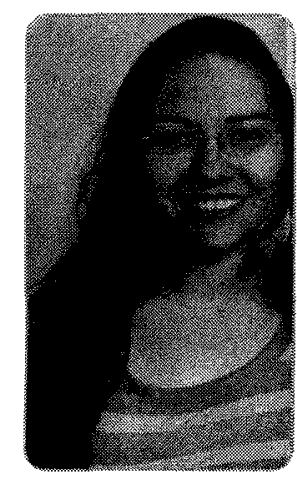

\section{Juliana Magalhães da Cunha Rêgo}

Endereço para acessar este CV: http://lattes.cnpq.br/1742923820297664

última atualização do currículo em 23/05/2013

Nutricionista. Especialista em Nutrição Clínica: Fundamentos Metabólicos e Nutricionais pela Universidade Gama Filho. Mestre em Ciências - Área de concentração: Nutrição em Saúde Pública da Faculdade de Saúde Pública na Universidade de São Paulo. Docente do Curso de Nutrição das Faculdades INTA - Instituto Superior de Teologia Aplicada, responsável pelas disciplinas Nutrição Humana I, Nutrição Humana II, Ética Profissional e Legislação em Nutrição e Estágio supervisionado em Nutrição Clínica. (Texto informado pelo autor)

\section{Identificação}

Nome Juliana Magalhães da Cunha Rêgo

Nome em citações bibliográficas RÊGO, J. M. C.

\section{Endereço}

\section{Endereço Profissional}

Instituto Superior de Teologia Aplicada, Curso de Nutrição.

Rua Cel. Antônio Rodrigues Magalhães, 359

Dom Expedito

62050100 - Sobral, CE - Brasil

Telefone: (88) 36143232

URL da Homepage: http://www. inta.edu.br/2013/

\section{Formação acadêmica/titulação}

$2011-2013$

$2010-2011$
Mestrado em Nutrição em Saúde Pública.

Universidade de São Paulo, USP, Brasil.

Título: Associação entre alterações do estado nutricional, perda dentária, uso de prótese e autopercepção das condições bucais de idosos no município de São Paulo: Estudo SABE (2000 e 2006), Ano de Obtenção: 2013.

Orientador: 9 Maria de Fátima Nunes Marucci.

Bolsista do(a): Coordenação de Aperfeiçoamento de Pessoal de Nível Superior, CAPES, Brasil.

Palavras-chave: idoso; autopercepção; condições bucais; Estado Nutricional.

Especialização em Pós-Graduação Lato Sensu em Nutrição Clínica. (Carga Horária: 500h).

Universidade Gama Filho, UGF, Brasil.

Título: Correlação de estado nutricional, úlcera de pressão, mobilidade e nutrição enteral de pacientes em Home Care.

Orientador: Cezar Henrique de Azevedo.
Graduação em Nutrição - Bacharelado.

Universidade Estadual do Ceará, UECE, Brasil.

Título: Interrelações entre İndice Glicêmico, Carga Glicêmica e Estado

Nutricional: uma avaliação de crianças e adolescentes de escolas públicas e

particulares da periferia de Fortaleza - Ceará.

Orientador: Helena Alves de Carvalho Sampaio.

Bolsista do(a): Conselho Nacional de Desenvolvimento Científico e Tecnológico, 


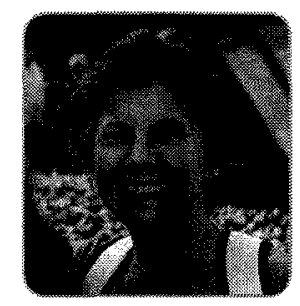

\section{Maria de Fátima Nunes Marucci}

Endereço para acessar este CV: http://lattes.cnpq.br/4869162380172913

última atualização do currículo em 10/01/2013

Nutricionista (1977), Mestre (1985) e Doutora (1992) em Saúde Pública, na área de concentração Nutrição, pela Faculdade de Saúde Pública (FSP), Universidade de São Paulo (USP). Professora do Departamento de Nutrição, FSP/USP, desde $1^{\circ}$ de agosto de 1978. Professora responsável por disciplinas: do Curso de Graduação em Nutrição (FSP/USP): HNT 150 - Dietoterapia e HNT 198 - Nutrição Clínica, e disciplina do Curso de pós-graduação (FSP/USP) HNT 5717 -Nutrição em Gerontologia. Orientadora de alunos de iniciação científica, mestrado e doutorado, nas áreas de alimentação e nutrição, com ênfase em avaliação nutricional de adultos e idosos; epidemiologia nutricional e dietética. Professora credenciada no programa de pós-graduação da USP: Nutrição em Saúde Pública (FSP). (Texto informado pelo autor)

\section{Identificação}

$\begin{array}{ll}\text { Nome } & \text { Maria de Fátima Nunes Marucci } \\ \text { Nome em citações bibliográficas } & \text { MARUCCI, M.F.N. }\end{array}$

\section{Endereço}

\section{Formação acadêmica/titulação}

1986 - 1992

$1980-1985$
Doutorado em Saúde Pública (Conceito CAPES 5).

Universidade de São Paulo, USP, Brasil.

Título: Aspectos nutricionais e hábitos alimentares de idosos matriculados em ambulatório geriátrico, Ano de obtenção: 1992.

Orientador: Donald Wilson.

Palavras-chave: Alimentação de idosos.

Grande área: Ciências da Saúde / Área: Saúde Coletiva / Subárea: Saúde Pública.

Grande Área: Ciências da Saúde / Área: Nutrição / Subárea: Análise Nutricional de População.

Grande Área: Ciências da Saúde / Área: Nutrição.

Setores de atividade: Nutrição e Alimentação; Saúde Humana.

Mestrado em Saúde Pública (Conceito CAPES 5).

Universidade de São Paulo, USP, Brasil.

Título: Avaliação das dietas oferecidas em instituições para idosos, localizadas no Município de São Paulo,Ano de Obtenção: 1985.

Orientador: Donald Wilson.

Grande área: Ciências da Saúde / Área: Nutrição / Subárea: Dietética.

Grande Área: Ciências da Saúde / Área: Saúde Coletiva / Subárea: Saúde Pública.

Setores de atividade: Nutrição e Alimentação; Saúde Humana. 